\title{
Molecular mechanisms and associated cell signalling pathways underlying the anticancer properties of phytochemical compounds from Aloe species (Review)
}

\author{
HANNA SVITINA $^{1,2}$, JOSIAS H. HAMMAN ${ }^{1}$ and CHRISNA GOUWS ${ }^{1}$ \\ ${ }^{1}$ Centre of Excellence for Pharmaceutical Sciences (Pharmacen ${ }^{\mathrm{TM}}$ ), North-West University, \\ Potchefstroom, North West 2520, South Africa; ${ }^{2}$ Department of Functional Genomics, \\ Institute of Molecular Biology and Genetics of NASU, Kyiv 03143, Ukraine
}

Received December 15, 2020; Accepted May 7, 2021

DOI: $10.3892 /$ etm.2021.10284

\begin{abstract}
Naturally occurring components from various species of Aloe have been used as traditional folk medicine since the ancient times. Over the last few decades, the therapeutic effects of extracts and phytochemical compounds obtained from Aloe vera have been proven in preclinical and clinical studies. Recently, compounds from other Aloe species apart from Aloe vera have been investigated for the treatment of different diseases, with a particular focus on cancer. In the present review, the effects of phytochemical compounds obtained from different Aloe species are discussed, with a specific focus on the effects on cell signalling in cancer and normal cells, and their selectivity and efficacy. This information will be useful for the application of Aloe-derived compounds as therapeutic agents, either alone or in combination with other standard drugs for cancer treatment.
\end{abstract}

\section{Contents}

1. Introduction

2. Cell death initiation by the phytochemical compounds of Aloe

3. Anticancer selectivity

4. Cell cycle regulation

5. Cell signalling

6. Angiogenesis

7. Migration and invasion

Correspondence to: Dr Hanna Svitina, Centre of Excellence for Pharmaceutical Sciences (Pharmacen ${ }^{\mathrm{TM}}$ ), North-West University, Private Bag X6001, 11 Hoffman Street, Potchefstroom, North West 2520, South Africa

E-mail: anja.onishchenko@gmail.com

Key words: xanthorrhoeaceae, Aloe vera, traditional medicine, cell signalling, cancer
8. Inflammation and immunomodulation $(\mathrm{TNF}-\alpha / \mathrm{NF}-\kappa \mathrm{B}$ pathway)

9. Recommendations for future applications

10. Conclusions

\section{Introduction}

The genus Aloe belongs to the family of Xanthorrhoeaceae and includes $\sim 400$ xerophyte plant species grown all over the world. Due to their ability to survive in hot and dry conditions, Aloe plants tend to store water and important chemical constituents in their swollen and succulent leaves, which makes them a unique source of phytochemicals (1).

Combinations of active molecules extracted from Aloe species have been indicated to confer a variety of biological effects with different mechanisms of action (2). The most extensively studied Aloe species is Aloe vera (A. vera), the official name of which is $A$. barbadensis, which has been used as a form of medicine since the ancient times. In the period from 2014 to 2019, 35 clinical trials have been initiated to study the clinical efficacy of $A$. vera plant extracts (2). The $A$. vera plant has an estimated annual commercial market value of \$US 13 billion $(3,4)$. A. vera has a large number of reported phytochemical constituents that are able to improve skin disorders (5), diabetes $(6,7)$, fibrosis (8), periodontitis (9), bone regeneration (10) and irritable bowel syndrome (11) through different mechanisms of actions. As pointed out by The International Aloe Science Council (https://www.iasc.org), extracts from other Aloe species, including A. arborescens, A. arborescence var. nataliensis, A. mutabilis, A. ferox, A. candelabrum, A. africana and A. spicata, also possess medicinal properties (12-17).

A previous randomised clinical trial performed by Lissoni et al (12) investigated 240 patients with different types metastatic solid tumour who received chemotherapy alone or chemotherapy in combination with orally administered A. arborescens. This study indicated that A. arborescens combined with chemotherapy was more effective in terms of the degree of oncostatic effect, tumour regression rate and survival time, in addition to reductions in adverse events. 
Furthermore, the patient group who received Aloe exhibited prolonged survival times and had an improved quality of life, particularly in terms of asthenia relief and fatigue (12).

The effects of phytochemicals on cell signalling are currently a topic of intense research (18-21). Of note, medicinal plants have been the source of numerous anticancer drugs that are currently used in chemotherapy, including vincristine, irinotecan, etoposide and paclitaxel (22). Therefore, interest in the potential anticancer activity of herbal compounds is gaining attention (23). Approximately 20 chemical constituents have been reported as the major biologically active components within the extracts of Aloe species (24-27). These phytochemicals include anthraquinones (aloe-emodin, emodin and chrysophanol), anthranols (aloin A, aloin B, aloinoside A, aloinoside $\mathrm{B}$ and aloesaponol), chromones (aloesin and aloesone), coumarins (esculetin and umbelliferone), pyrans and pyrones (aloenin), flavonoids (isovitexin), naphthalene derivatives (plicataloside) and polysaccharides (acemannan) (24-27). The potential pharmacological benefits of the bioactive components of plants belonging to the Aloe genus have been reviewed in a recent publication (28). Aloe-derived phytochemicals have been successfully applied for treating a broad range of conditions. Indeed, $A$. vera extract has been previously demonstrated to confer renoprotective action (29), radioprotective potential (30) and virustatic effects (31). In addition, aloe- emodin has been documented to ameliorate renal interstitial fibrosis (32), whilst aloin demonstrated selective effects against Leishmania aethiopica and Leishmania donovani (33) and isovitexin was indicated to be an anti-diabetic $(34,35)$ and neuroprotective (36) compound. Acemannan may also be used as a matrix for bone regeneration (37-39).

The present review discusses the different signalling activities that are associated with the anticancer effects of pure phytochemical compounds derived from Aloe extracts, aiming to provide insight into the target mechanisms of action underlying the pharmacological effects of Aloe components.

\section{Cell death initiation by the phytochemical compounds of Aloe}

General. Cell death is a tightly regulated process in multicellular organisms (40). There are three types of cell death: Apoptosis (type I cell death), Autophagic cell death (type II cell death) and necrosis (type III cell death) (41-43). Apoptosis is known as a programmed cell death and dysregulation of apoptosis may lead to various health conditions, e.g. potentiation of apoptosis may be associated with neurodegenerative or autoimmune diseases, while suppression of apoptosis may lead to cancer (44). Therefore, one of the most widely studied anticancer strategies is targeting the apoptotic cascade (45). Since the third form of cell death, necrosis, is characterized by the rapid loss of plasma membrane integrity and spillage of its intracellular contents (43), the tiggering of necrosis is not a valuable strategy for cancer treatments, which is why it is not discussed further. The influence of the pure phytochemical compounds from Aloe extracts on cell death-associated pathways are discussed in this section.

Intrinsic pathway of caspase-3 dependent apoptosis initiation The intrinsic or mitochondrial apoptosis pathway is triggered by mitochondrial outer membrane permeabilisation and the loss of the mitochondrial membrane potential $(\Delta \Psi \mathrm{m})$, which is in turn mediated by the oligomerisation of Bcl-2-like protein 4 (BAX) or Bcl-2 associated agonist of cell death. Reactive oxygen species (ROS) may also cause mitochondrial membrane depolarisation and the opening of $\mathrm{BAX} / \mathrm{Bcl}-2$ homologous antagonist killer (BAK) channels (46). After membrane disruption, cytochrome $c$ is released from mitochondria into the cytoplasm, which binds with the apoptotic protease activating factor 1 (Apaf-1) protein to form the apoptosome and activate the caspase cascade, resulting in apoptosis (44). Mitochondrial outer membrane permeabilisation is antagonised by the anti-apoptotic Bcl-2-family of proteins, which under physiological conditions are bound to the BAX/BAK channels to inhibit their function (41). Following caspase cascade activation, cleavage of poly(ADP-ribose) polymerase (PARP-1) by caspases is considered to be the hallmark of apoptosis $(47,48)$.

A summary of the effects of selected Aloe compounds on intrinsic apoptosis activation on different types of cancer is presented in Table I and Fig. S1. Pure compounds extracted from Aloe potently activated the intrinsic apoptotic pathway of cancer cells. However, the effect of crude Aloe extracts has not been studied extensively. The lyophilised $A$. vera extract from the Coral Vegetable (Miyakojima, Japan) has been reported to possess the ability to reduce BCL2 gene expression in the human hepatoblastoma HepG2 cell line (49). By contrast, treatment of the human neuroblastoma cell line IMR-32 with $A$. vera protein extract did not result in any differences in the relative expression levels of BAX, BCL2 and the cell survival-related gene myeloid cell leukaemia 1 (50), suggesting that the active components that exerted effects on these genes were unlikely to be of protein origin. Supporting this, crude A. arborescens whole-leaf extract was unable to induce the cleavage of PARP-1 or induce apoptosis according to the results from a Annexin V assay in spontaneously-immortalised HaCaT human skin keratinocytes, which are not cancerous, further suggesting that Aloe treatment did not trigger apoptosis (51).

Aloe-emodin has been indicated to induce apoptosis by upregulating the protein expression of BAX and caspases-9 and -3 , whilst decreasing that of Bcl-2, thereby inducing the loss of $\Delta \Psi \mathrm{m}$, cytochrome $c$ release into the cytosol and increasing the levels of ROS. These effects were demonstrated in the human breast cancer cell lines MCF10AT and MCF7 (52), the human pancreatic adenocarcinoma cell line MIAPaCa-2 (53), the human colorectal cancer cell lines SW620 and HT29 (54), the human oral squamous cell carcinoma cell line SCC15 (55), the human stomach cancer cell line AGS (56) and in human non-small cell lung cancer (57). Immunohistochemical staining for caspase-3 in sections of xenograft tumours formed by U87MG cells in CD1 nude mice was evidently stronger in tumour tissues from mice treated with aloe-emodin (58). Furthermore, reduction of PARP-1 (116 kDa) and activation of lamin A was detected in U87MG human glioblastoma cell line treated with aloe-emodin (58). In addition, aloe-emodin has been reported to decrease the apoptosis rate, ROS production and $\Delta \Psi \mathrm{m}$ in $\mathrm{H}_{2} \mathrm{O}_{2}$-treated neonatal rat ventricular cardiomyocytes but did not confer any effect on cardiomyocytes that were not exposed to $\mathrm{H}_{2} \mathrm{O}_{2}$, providing an example of the safety of Aloe compounds for non-cancerous cells (59). 
Table I. Effects of phytochemical compounds from Aloe species on signalling networks in cancer models.

A, Apoptosis: Intrinsic pathway of apoptosis initiation, caspase-3 dependent

\begin{tabular}{ll}
\hline Compound & \multicolumn{1}{c}{ Model } \\
\hline $\begin{array}{l}\text { Lyophilized } \\
\text { A. vera extract }\end{array}$ & Human hepatoblastoma HepG2 cell line \\
$\begin{array}{l}\text { A. vera protein } \\
\text { extract }\end{array}$ & Human neuroblastoma cell line IMR-32 cell line \\
Aloe-emodin & Human breast cancer MCF-10AT and MCF-7 cell \\
& lines \\
& Human glioblastoma U87MG cell line \\
& U87MG xenograft tumours in CD1 nude mice \\
& Human pancreatic adenocarcinoma \\
& MIAPaCa-2 cell line \\
& Human colorectal cancer cells SW620 and HT29 \\
& Human oral squamous cell carcinoma \\
& SCC15 cell line \\
& Human lung adenocarcinoma A549 and \\
& NCI-H1299 cell lines
\end{tabular}

Gamma-irradiated Human stomach cancer AGS cell line aloe-emodin

Emodin

Human cervical cancer HeLa cell line

HeLa

Human hepatocarcinoma SMMC-7721 cell line

HepG2

Human hepatocarcinoma HepaRG cell line

Human pancreatic cancer SW1990 cell line

SW1990-inoculated nude mice

Human lung adenocarcinoma cells A549

A549

IMR-32

Human colorectal carcinoma SW480 and SW620 cell lines

(Refs.)

$\downarrow$ BCL2 gene expression

no differences in BAX, BCL2 and

MCL1 mRNA expression

$\downarrow \mathrm{Bcl}-2, \downarrow \mathrm{Bcl}-\mathrm{xL}, \uparrow \mathrm{BAX}$

$\downarrow$ of the non-cleaved form of PARP-1, activation of lamin $\mathrm{A}$

Activation of caspase 3

DNA fragmentation and $\downarrow \Delta \Psi \mathrm{m}$

$\downarrow \mathrm{Bcl}-2, \uparrow \mathrm{BAX}, \uparrow \mathrm{ROS}$

$\uparrow$ caspase- $9, \uparrow$ caspase- 3

$\uparrow$ caspase-9, $\uparrow$ caspase- $3, \uparrow$ cleaved

caspase-3, $\uparrow$ cleaved caspase-9,

$\uparrow$ cleaved PARP

$\uparrow$ BAX, $\uparrow$ caspase-9, $\uparrow$ caspase-3,

$\uparrow$ cytosolic cytochrome c release,

$\uparrow$ ROS, $\uparrow$ caspase-8-mediated BID and

PARP-1 cleavage, $\downarrow \Delta \Psi \mathrm{m}, \downarrow \mathrm{Bcl}-2$

$\uparrow$ cytochrome c, $\uparrow$ Apaf- 1 ,

$\downarrow$ pro-caspase-9, $\downarrow$ pro-caspase-3

$\uparrow$ cleavage of pro-caspases,

$\uparrow$ the ratio of BAX to $\mathrm{Bcl}-2$ proteins

$\uparrow$ cleaved caspase- 3 ,

$\uparrow$ cleaved caspase-9

$\uparrow$ cyclophilin D $\downarrow \Delta \Psi \mathrm{m}, \downarrow$ ATP

production, $\uparrow$ oxygen anion $\left(\mathrm{O}_{2}^{-}\right)$

generation in mitochondria

$\uparrow$ ROS $, \downarrow \Delta \Psi \mathrm{m}, \uparrow$ cytochrome c

release from mitochondria, $\uparrow \mathrm{BAX}$,

$\uparrow$ cleaved caspase- $3, \uparrow$ cleaved

caspase-9, $\uparrow$ cleaved PARP, $\downarrow$ Bcl-2

$\downarrow$ Bcl-2, $\uparrow \mathrm{BAX}, \uparrow$ cytochrome c

(cytosol), $\uparrow$ caspase-9, $\uparrow$ caspase-3

$\downarrow$ Bcl-2 to BAX ratio, $\uparrow$ caspase-9,

$\uparrow$ caspase- $3, \uparrow$ cytochrome c release

$\uparrow$ cytochrome c, $\uparrow$ caspase- 3 ,

$\uparrow$ caspase-9, $\uparrow$ generation of ROS

$\downarrow \Delta \Psi \mathrm{m}, \downarrow \mathrm{Bcl}-2, \uparrow \mathrm{BAX}$

$\uparrow \mathrm{BAX}, \downarrow$ Survivin, $\uparrow$ cytosolic

cytochrome c, $\downarrow \Delta \Psi \mathrm{m}$,

$\uparrow$ ROS generation

$\uparrow$ ROS,$\uparrow$ cytoplasmic free

calcium $\left(\mathrm{Ca}^{2+}\right)$ and NO levels,

$\downarrow \Delta \Psi \mathrm{m}, \uparrow$ caspases-9, $\uparrow$ caspase-3

$\uparrow \operatorname{ROS}$ 
Table I. Continued.

A, Apoptosis: Intrinsic pathway of apoptosis initiation, caspase-3 dependent

\begin{tabular}{|c|c|c|c|}
\hline Compound & Model & Target & (Refs.) \\
\hline \multirow[t]{7}{*}{ Chrysophanol } & $\begin{array}{l}\text { Human breast cancer MCF-7 and } \\
\text { MDA-MB-231 cell lines }\end{array}$ & $\begin{array}{l}\uparrow \text { cleaved caspase } 3, \\
\uparrow \text { cleaved PARP-1, } \downarrow \text { Bcl-2 }\end{array}$ & $(71)$ \\
\hline & Human breast cancer BT-474 and MCF-7 cell lines & $\begin{array}{l}\downarrow \Delta \Psi \mathrm{m}, \uparrow \text { cytosolic } \mathrm{Ca}^{2+}, \uparrow \mathrm{BAX}, \\
\uparrow \text { cytochrome c expression, } \uparrow \mathrm{ROS}\end{array}$ & $(72)$ \\
\hline & A549 & $\begin{array}{l}\uparrow \mathrm{ROS}, \downarrow \Delta \Psi \mathrm{m}, \uparrow \text { cytochrome } \mathrm{c}, \\
\uparrow \mathrm{DNA} \text { damage, did not alter the total } \\
\text { protein levels of PARP, caspase- } 3, \\
\text { Apaf-1 and AIF }\end{array}$ & $(75)$ \\
\hline & $\begin{array}{l}\text { Human small (H738) and non-small cell } \\
\text { lung cancer (A549) cell lines }\end{array}$ & $\begin{array}{l}\uparrow \mathrm{BAX}, \uparrow \text { caspase- } 3, \uparrow \text { caspase-9, } \\
\uparrow \mathrm{PARP}-1, \downarrow \mathrm{Bcl}-2, \downarrow \Delta \Psi_{\mathrm{m}}\end{array}$ & $(72)$ \\
\hline & Human hepatocellular carcinoma J5 cell line & $\begin{array}{l}\uparrow \mathrm{ROS}, \uparrow \text { cytosolic } \mathrm{Ca}^{2+} \text { level, } \\
\uparrow \mathrm{DNA} \text { damage, } \downarrow \Delta \Psi \mathrm{m}\end{array}$ & $(74)$ \\
\hline & Human choriocarcinoma JEG-3 cell line & $\uparrow \operatorname{ROS}, \downarrow \Delta \Psi \mathrm{m}$ & $(76)$ \\
\hline & Human renal cell carcinoma Caki-2 cell line & $\begin{array}{l}\uparrow \text { ROS, no changes in the protein } \\
\text { levels of cleaved caspase- } 3 \text { and } \\
\text { cleaved PARP }\end{array}$ & $(77)$ \\
\hline \multirow[t]{5}{*}{ Aloin } & $\begin{array}{l}\text { Human gastric cancer BGC-823 and HGC- } 27 \text { cell } \\
\text { lines }\end{array}$ & $\downarrow$ ROS & $(78)$ \\
\hline & HGC-27 & $\uparrow$ cleaved PARP, $\uparrow$ cleaved caspase- 3 & (79) \\
\hline & $\begin{array}{l}\text { Human hepatocellular carcinoma HepG2 and } \\
\text { Bel-7402 }\end{array}$ & $\begin{array}{l}\uparrow \text { cleaved caspase }-3, \\
\uparrow \text { cleaved caspase- } 9\end{array}$ & $(80)$ \\
\hline & A549 & $\begin{array}{l}\uparrow \mathrm{BAK}, \uparrow \mathrm{BAX}, \uparrow \mathrm{PUMA}, \uparrow \mathrm{NOX}, \\
\uparrow \text { cleaved caspase- } 3, \\
\uparrow \text { cleaved caspase- } 9, \downarrow \Delta \Psi \mathrm{m}, \\
\uparrow \text { release of mitochondrial } \mathrm{Ca}^{2+}\end{array}$ & $(81)$ \\
\hline & SW620 & $\downarrow \mathrm{Bcl}-\mathrm{xL}$ & $(82)$ \\
\hline \multirow[t]{2}{*}{ Aloesin } & Human ovarian cancer SKOV3 cell line & $\begin{array}{l}\uparrow \text { cleavage of caspase- } 3, \\
\uparrow \text { cleavage of caspase- } 9, \\
\uparrow \text { cleavage of and PARP- } 1, \\
\uparrow \text { BAX, } \downarrow \text { Bcl- } 2\end{array}$ & $(87)$ \\
\hline & $\begin{array}{l}\text { SKOV3 xenograft model of ovarian cancer in } \\
\text { athymic nude mice }\end{array}$ & $\begin{array}{l}\text { More apoptotic cells by detection of } \\
\text { cleaved caspase- } 3 \text { in tumour }\end{array}$ & $(87)$ \\
\hline \multirow[t]{6}{*}{ Esculetin } & $\begin{array}{l}\text { Human pancreatic cancer cell lines (PANC-1, } \\
\text { MIAPaCa- } 2 \text { and AsPC-1) }\end{array}$ & $\begin{array}{l}\uparrow \text { caspase- } 3, \uparrow \text { caspase- } 9, \\
\uparrow \text { cleaved caspase- } 3, \\
\uparrow \text { cleaved caspase-9, } \uparrow \text { cytochrome c, } \\
\downarrow \Delta \Psi \mathrm{m}, \downarrow \text { ROS }\end{array}$ & $(88)$ \\
\hline & Human prostate cancer PC-3 cell line & $\begin{array}{l}\uparrow \text { mRNA expressions of CASP3, } \\
\text { BAX and CYCS (cytochrome c), } \\
\downarrow \text { mRNA expressions of BCL2 }\end{array}$ & (89) \\
\hline & Human laryngeal cancer HEp-2 cell line & $\uparrow \operatorname{ROS}$ & $(93)$ \\
\hline & Human gastric cancer MGC-803 cell line & $\begin{array}{l}\downarrow \Delta \Psi \mathrm{m}, \uparrow \text { cytochrome c release, } \\
\downarrow \text { Bcl-2/BAX ratio, } \uparrow \text { caspase- } 9, \\
\uparrow \text { caspase- } 3 \text { activity }\end{array}$ & $(90)$ \\
\hline & MGC-803 xenograft model in nude mice & $\uparrow$ caspase-3, $\downarrow$ Bcl-2, $\downarrow$ Ki-67 & $(90)$ \\
\hline & SMMC-7721 & $\begin{array}{l}\downarrow \Delta \Psi \mathrm{m}, \uparrow \text { cytochrome c release, } \\
\downarrow \mathrm{Bcl}-2, \uparrow \mathrm{BAX}, \uparrow \text { caspase- } 9, \\
\uparrow \text { caspase-3 }\end{array}$ & $(91)$ \\
\hline \multirow[t]{2}{*}{ Umbelliferone } & Human oral carcinoma KB cell line & $\uparrow \operatorname{ROS}, \downarrow \Delta \Psi \mathrm{m}$ & $(94)$ \\
\hline & $\begin{array}{l}\text { Human renal cell carcinoma }(786-\mathrm{O} \text {, } \\
\text { OS-RC-2 and ACHN) cell lines }\end{array}$ & $\uparrow \mathrm{BAX}, \downarrow \mathrm{Ki}-67, \downarrow \mathrm{MCM}-2, \downarrow \mathrm{Bcl}-2$ & $(92)$ \\
\hline
\end{tabular}


Table I. Continued.

A, Apoptosis: Intrinsic pathway of apoptosis initiation, caspase-3 dependent

\begin{tabular}{|c|c|c|c|}
\hline Compound & Model & Target & (Refs.) \\
\hline \multirow[t]{3}{*}{ Isovitexin } & $\begin{array}{l}\text { Human liver cancer (HepG2 and SK-Hep1) } \\
\text { cell lines }\end{array}$ & $\begin{array}{l}\uparrow \text { caspase- } 3 \text { cleavage, } \uparrow \text { PARP } \\
\text { cleavage, } \uparrow \text { BAX, } \uparrow \text { cytochrome c } \\
\text { release }, \downarrow \text { Bcl- } 2\end{array}$ & (95) \\
\hline & HepG2 tumour-bearing mice & $\uparrow$ cleaved caspase- $3, \uparrow$ cleaved PARP & $(95)$ \\
\hline & HeLa & $\downarrow \mathrm{Bcl}-2, \uparrow \mathrm{BAX}, \uparrow$ caspase-3 & (96) \\
\hline
\end{tabular}

B, Apoptosis: Intrinsic pathway of apoptosis initiation, p53-dependent

\begin{tabular}{|c|c|c|c|}
\hline Compound & Model & Target & (Refs.) \\
\hline $\begin{array}{l}\text { Lyophilized } \\
\text { A. vera extract }\end{array}$ & HepG2 & $\uparrow$ P53 mRNA expression & $(49)$ \\
\hline Aloe-emodin & U87MG xenograft CD1 nude mice & $\uparrow \mathrm{p} 53$ & $(58)$ \\
\hline Emodin & $\begin{array}{l}\text { A549 } \\
\text { IMR-32 } \\
\text { HepaRG }\end{array}$ & $\begin{array}{l}\text { Activated ROS-elicited ATM-p53-Bax } \\
\uparrow \mathrm{p} 53, \uparrow \mathrm{p} 21 \\
\uparrow \mathrm{p} 53\end{array}$ & $\begin{array}{l}(67) \\
(68) \\
(63)\end{array}$ \\
\hline Aloin & A549 & $\begin{array}{l}\uparrow \text { phosphorylation of p53 in Ser15, } \\
\text { Thr18, Ser20 and Ser392 sites }\end{array}$ & $(84)$ \\
\hline
\end{tabular}

C, Apoptosis: Extrinsic pathway of apoptosis initiation

\begin{tabular}{|c|c|c|c|}
\hline Compound & Model & Target & (Refs.) \\
\hline Aloe-emodin & U87MG xenograft tumour tissue in CD1 nude mice & $\uparrow$ caspase- 8 & $(58)$ \\
\hline $\begin{array}{l}\text { Gamma-irradiated } \\
\text { aloe-emodin }\end{array}$ & AGS & $\uparrow$ caspase- 8 protein & $(56)$ \\
\hline \multirow[t]{2}{*}{ Emodin } & $\mathrm{HeLa}$ & $\begin{array}{l}\uparrow \text { Fas }, \uparrow \text { FasL }, \uparrow \text { FADD, } \\
\downarrow \text { pro-caspase- } 8\end{array}$ & $(60)$ \\
\hline & HepaRG & $\uparrow$ cleaved caspase- 8 & $(63)$ \\
\hline Chrysophanol & Caki-2 & $\downarrow$ DR5,$\downarrow$ RIP1,$\downarrow$ RIP3 & $(77)$ \\
\hline \multirow[t]{2}{*}{ Esculetin } & PANC-1, MIAPaCa-2 and AsPC-1 & $\uparrow$ caspase- $8, \uparrow$ cleaved caspase- 8 & $(88)$ \\
\hline & $\mathrm{PC}-3$ & $\uparrow$ mRNA expressions of CASP8 & $(89)$ \\
\hline \multicolumn{4}{|l|}{ D, Autophagy } \\
\hline Compound & Model & Target & (Refs.) \\
\hline \multirow[t]{2}{*}{ Aloe-emodin } & MIAPaCa-2 & $\uparrow$ conversion of LC3-I to LC3-II & $(53)$ \\
\hline & A549 and NCI-H1299 & $\uparrow \mathrm{LC} 3-\mathrm{II}, \uparrow$ Beclin 1 & $(57)$ \\
\hline \multirow[t]{2}{*}{ Isovitexin } & HepG2 and SK-Hep1 & $\uparrow \mathrm{LC} 3, \uparrow \operatorname{Atg} 3, \uparrow \operatorname{Atg} 5, \uparrow$ Beclin 1 & $(95)$ \\
\hline & HepG2 tumour-bearing mice & $\uparrow$ LC3II level in tumour tissue & $(95)$ \\
\hline
\end{tabular}

E, Cell cycle

\begin{tabular}{lll}
\hline Compound & \multicolumn{1}{c}{ Model } & \multicolumn{1}{c}{ Target } \\
\hline $\begin{array}{l}\text { Crude whole-leaf } \\
\text { A. arborescens }\end{array}$ & $\begin{array}{l}\text { Human epidermoid skin carcinoma A431 cell } \\
\text { extract }\end{array}$ & $\begin{array}{l}\uparrow \text { p21WAF } \\
\text { adenocarcinoma Caco-2 cell line }\end{array}$ \\
& Caco-2 and MDA-MB231 & \\
Aloe-emodin & U87MG & $\begin{array}{l}\downarrow \text { cyclin D1 } \\
\end{array}$ \\
& & Cell cycle arrest in S andG2/M phases, \\
& & p53, $\uparrow$ p21, $\downarrow$ CDK2
\end{tabular}

(Refs.)

Crude whole-leaf Human epidermoid skin carcinoma A431 cell 
Table I. Continued.

\begin{tabular}{|c|c|c|c|}
\hline Compound & Model & Target & (Refs.) \\
\hline & MIAPaCa-2 & $\uparrow$ fraction of cells in sub-G1 phase & (53) \\
\hline & $\begin{array}{l}\text { EGF-induced transformed JB6 CI 41-5a } \\
\text { (mouse skin epidermis) cells }\end{array}$ & G1 phase arrest, $\downarrow$ cyclin D1 & (110) \\
\hline & MCF7 & $\downarrow$ cyclin D1 & (111) \\
\hline $\begin{array}{l}\text { Gamma-irradiated } \\
\text { aloe-emodin }\end{array}$ & AGS & $\uparrow$ sub-G1 peak & $(56)$ \\
\hline \multirow[t]{5}{*}{ Emodin } & MCF7 & $\downarrow$ cyclin D1 & (111) \\
\hline & IMR-32 & $\uparrow \mathrm{p} 21$ & $(68)$ \\
\hline & HepaRG & $\begin{array}{l}\mathrm{S} \text { and } \mathrm{G} 2 / \mathrm{M} \text { phases arrest }, \uparrow \mathrm{p} 21 \\
\uparrow \text { cyclin } \mathrm{E}, \downarrow \text { cyclin } \mathrm{A}, \downarrow \mathrm{CDK} 2\end{array}$ & (63) \\
\hline & SW480 and SW620 cells & $\begin{array}{l}\text { decrease in the expression of mRNA } \\
\text { as well as the protein of Myc and } \\
\text { cyclin D1 }\end{array}$ & (69) \\
\hline & $\begin{array}{l}\text { Human cervical cancer HeLa and } \mathrm{SiHa} \\
\text { cell lines }\end{array}$ & $\begin{array}{l}\downarrow \mathrm{p} 15, \downarrow \mathrm{p} 16, \downarrow \mathrm{p} 27, \downarrow \mathrm{CDK} 6, \\
\downarrow \text { cyclin D1, } \mathrm{p} 21, \downarrow \text { Pin } 1\end{array}$ & (61) \\
\hline \multirow[t]{3}{*}{ Chrysophanol } & A549 & $\begin{array}{l}\text { S-phase arrest, } \downarrow \text { cyclin } \mathrm{D}, \downarrow \text { CDK2, } \\
\downarrow \text { thymidylate synthase }\end{array}$ & (75) \\
\hline & $\mathrm{J} 5$ & $\mathrm{~S}$ phase arrest & (72) \\
\hline & MCF-7 and MDA-MB-231 & $\begin{array}{l}\text { cell cycle arrest at the G1-S cell cycle } \\
\text { checkpoint, } \downarrow \text { cyclin D1, } \downarrow \text { cyclin E, } \\
\uparrow \text { p } 21\end{array}$ & (71) \\
\hline Aloin & BGC-823 and HGC-27 & $\begin{array}{l}\text { S and G2 phase arrest, } \\
\downarrow \text { cyclin D1, unchanged cyclin E1 }\end{array}$ & (78) \\
\hline \multirow[t]{2}{*}{ Aloesin } & SKOV3 & $\downarrow$ cyclin $\mathrm{A}, \downarrow \mathrm{CDK} 2, \downarrow$ cyclin D1 & (87) \\
\hline & SK-HEP-1 & $\begin{array}{l}\uparrow \text { cyclin E, } \uparrow \text { CDK2, } \uparrow \text { CDC25A, } \\
\uparrow \text { enzyme activity of cyclin E/CDK2 }\end{array}$ & (112) \\
\hline \multirow[t]{4}{*}{ Esculetin } & PANC-1, MIAPaCa-2 and AsPC-1 & $\begin{array}{l}\uparrow \text { percentage of cells in G1 phase } \\
\text { with } \downarrow \text { percentage of cells in S and } \\
\text { G2/M phases }\end{array}$ & (88) \\
\hline & SMMC-7721 & $\downarrow$ c-Myc, $\downarrow$ cyclin D1 & (113) \\
\hline & $\begin{array}{l}\text { Human prostate cancer (PC-3, DU145 } \\
\text { and LNCaP) cell lines }\end{array}$ & G1-phase arrest & (89) \\
\hline & $\mathrm{PC}-3$ & $\begin{array}{l}\uparrow \mathrm{p} 53, \uparrow \mathrm{p} 21 \mathrm{Cip} 1, \uparrow \mathrm{p} 27 \mathrm{Kip} 1, \\
\downarrow \mathrm{CDK} 2, \downarrow \mathrm{CDK} 4, \downarrow \text { cyclin D1 }\end{array}$ & (89) \\
\hline \multirow[t]{2}{*}{ Umbelliferone } & KB & G0/G1 phase arrest & (94) \\
\hline & 786-O, OS-RC-2 and ACHN & $\begin{array}{l}\text { G1 phase arrest, } \downarrow \text { Ki67, } \downarrow \text { MCM2, } \\
\downarrow \text { CDK2, } \downarrow \text { cyclinE1, } \downarrow \text { CDK4, } \\
\downarrow \text { cyclinD } 1\end{array}$ & (92) \\
\hline
\end{tabular}

F, PI3K-AKT signalling

\begin{tabular}{|c|c|c|c|}
\hline Compound & Model & Target & (Refs.) \\
\hline \multirow[t]{3}{*}{ Aloe-emodin } & U87MG cells & $\begin{array}{l}\downarrow \text { phosphorylation of AKT serine } \\
\text { (p-AKT) }\end{array}$ & $(58)$ \\
\hline & JB6 CI 41-5a cell neoplastic model & $\begin{array}{l}\downarrow \text { EGF-induced phosphorylation of } \\
\text { MSK1, PDK1 and AKT }\end{array}$ & $(110)$ \\
\hline & A549 and NCI-H1299 & $\downarrow \mathrm{p}-\mathrm{AKT}, \downarrow \mathrm{p}-\mathrm{mTOR}$ & $(57)$ \\
\hline \multirow[t]{3}{*}{ Emodin } & SMMC-7721 & $\downarrow \mathrm{p}$-AKT, total AKT was unchanged & $(62)$ \\
\hline & SW1990-inoculated nude mice & $\downarrow$ p-AKT (Ser473) in tumour tissues & (70) \\
\hline & A549 & $\downarrow \mathrm{p}-\mathrm{AKT}$ & $(66)$ \\
\hline
\end{tabular}


Table I. Continued.

\begin{tabular}{|c|c|c|c|}
\hline \multicolumn{4}{|c|}{ F, PI3K-AKT signalling } \\
\hline Compound & Model & Target & (Refs.) \\
\hline \multirow{5}{*}{ Chrysophanol } & U87MG & $\downarrow$ phosphorylation of AKT/PKB & $(120)$ \\
\hline & U87MG bearing mice & $\downarrow \mathrm{p}-\mathrm{AKT}$ & $(120)$ \\
\hline & BT-474 and MCF-7 & $\downarrow$ p- AKT,$\downarrow$ p-P70S6K,$\downarrow$ p-S6K & $(73)$ \\
\hline & HCT116 and SW480 & $\begin{array}{l}\downarrow \mathrm{p}-\mathrm{PI} 3 \mathrm{~K}, \downarrow \mathrm{p}-\mathrm{AKT}, \text { total AKT and } \\
\text { PI3K were unchanged }\end{array}$ & $(121)$ \\
\hline & Human colon carcinoma SNU-C5 cell line & $\begin{array}{l}\downarrow \text { EGF-induced activation of EGFR, } \\
\text { AKT, mTOR, p70S6K }\end{array}$ & $(122)$ \\
\hline \multirow{3}{*}{ Aloin } & JEG-3 & $\uparrow \mathrm{p}-\mathrm{AKT}, \uparrow \mathrm{p}-\mathrm{P} 70 \mathrm{~S} 6 \mathrm{~K}$ & $(76)$ \\
\hline & BGC-823 and HGC-27 & $\begin{array}{l}\downarrow \text { phosphorylation and activation of } \\
\text { Src, AKT, mTOR, P70S6K and S6K }\end{array}$ & $(78)$ \\
\hline & HepG2 and Bel-7402 & $\downarrow \mathrm{p}-\mathrm{PI} 3 \mathrm{~K}, \downarrow \mathrm{p}-\mathrm{AKT}, \downarrow \mathrm{p}-\mathrm{mTOR}$ & $(80)$ \\
\hline \multirow{6}{*}{ Esculetin } & $\begin{array}{l}\text { HepG2 orthotopic xenograft tumours in } \\
\text { BALB/c athymic nude mice }\end{array}$ & $\downarrow \mathrm{p}-\mathrm{PI} 3 \mathrm{~K}, \downarrow \mathrm{p}-\mathrm{AKT}, \downarrow \mathrm{p}-\mathrm{mTOR}$ & $(80)$ \\
\hline & HGC-27 and rhHMGB1- induced HGC-27 cells & $\begin{array}{l}\downarrow \mathrm{p}-\mathrm{AKT}, \downarrow \mathrm{p}-\mathrm{mTOR}, \downarrow \mathrm{p}-\mathrm{P} 70 \mathrm{~S} 6 \mathrm{~K} \\
\downarrow \mathrm{p}-\mathrm{S} 6 \mathrm{~K}, \downarrow \mathrm{p}-4 \mathrm{EBP} 1\end{array}$ & $(79)$ \\
\hline & $\mathrm{PC}-3$ & $\uparrow \mathrm{PTEN}, \downarrow \mathrm{p}-\mathrm{AKT}$ & $(89)$ \\
\hline & MGC-803 & $\downarrow \mathrm{IGF}-1, \downarrow$ p-PI3K,$\downarrow$ p-AKT & $(90)$ \\
\hline & MGC-803 xenograft nude mice & $\begin{array}{l}\downarrow \mathrm{IGF}-1, \downarrow \text { p-PI3K, } \downarrow \text { p-AKT, total } \\
\text { PI3K and AKT were unchanged }\end{array}$ & $(90)$ \\
\hline & SMMC-7721 & $\downarrow \mathrm{IGF}-1, \downarrow$ p-PI3K,$\downarrow$ p-AKT & $(91)$ \\
\hline Umbelliferone & 786-O, OS-RC-2 and ACHN & $\downarrow \mathrm{p} 110 \gamma$ & $(92)$ \\
\hline \multicolumn{4}{|c|}{ G, JAK-STAT signalling } \\
\hline Compound & Model & Target & (Refs.) \\
\hline Aloin & BGC-823 and HGC-27 & $\downarrow$ p-STAT3 & $(92)$ \\
\hline Esculetin & $\begin{array}{l}\text { HEp-2 in vitro and in HEp-2 xenograft } \\
\text { tumours in nude mice in vivo }\end{array}$ & $\downarrow$ p-JAK $1, \downarrow$ p-JAK2, $\downarrow$ p-STAT3 & $(93)$ \\
\hline $\begin{array}{l}\text { Aloe } \\
\text { polysaccharides }\end{array}$ & $\begin{array}{l}\text { HT-29 in vitro and } \\
2,4,6 \text {-trinitrobenzenesulfonic } \\
\text { acid-induced colitis in Sprague Dawley } \\
\text { rats in vivo }\end{array}$ & $\begin{array}{l}\downarrow \mathrm{JAK} 2, \downarrow \text { p-JAK2, } \downarrow \text { STAT-3, } \\
\downarrow \text { p-STAT3 }\end{array}$ & $(129)$ \\
\hline
\end{tabular}

H, MAPK-ERK signalling

\begin{tabular}{llll}
\hline Compound & \multicolumn{1}{c}{ Model } & \multicolumn{2}{c}{ Target } \\
\hline Emodin & SMMC-7721 & $\uparrow$ p-ERK, total ERK was unchanged & $(62)$ \\
& HepG2 & $\downarrow$ p-ERK & $(64)$ \\
& A549 & $\downarrow$ p-ERK & $(66)$ \\
& U87MG & $\downarrow$ p-ERK1/2 & $(120)$ \\
& U87MG bearing mice & $\downarrow$ p-ERK1/2 & $(120)$ \\
Chrysophanol & Modelled benign prostatic hyperplasia in rats and & $\downarrow$ p-ERK & $(105)$ \\
& in RWPE-1 cell line & & \\
& BT-474 and MCF-7 & $\downarrow$ p-ERK1/2 & $(73)$ \\
& JEG-3 & $\uparrow$ p-ERK1/2, $\uparrow$ p-P90RSK & $(76)$ \\
Aloin & SNU-C5 & $\downarrow$ EGF-induced activation of ERK1/2 & $(122)$ \\
Aloesin & HGC-27 and rhHMGB1-induced HGC-27 & $\downarrow$ p-ERK, $\downarrow$ p-P90RSK, $\downarrow$ p-CREB & $(79)$ \\
& SKOV3 & $\downarrow$ p-ERK, $\downarrow$ p-MEK & $(87)$
\end{tabular}


Table I. Continued.

I, MAPK-JNK/p38 signalling

\begin{tabular}{|c|c|c|c|}
\hline Compound & Model & Target & (Refs.) \\
\hline Emodin & SMMC-7721 & $\uparrow \mathrm{p}-\mathrm{p} 38, \downarrow \mathrm{p}-\mathrm{JNK}$ & $(62)$ \\
\hline \multirow[t]{2}{*}{ Chrysophanol } & BT-474 & $\downarrow$ p-p38, $\downarrow$ p-JNK & (73) \\
\hline & MCF-7 & $\uparrow \mathrm{p}-\mathrm{p} 38, \uparrow \mathrm{p}-\mathrm{JNK}$ & (73) \\
\hline Aloin & A549 & $\uparrow \mathrm{p}$-c-Jun, $\uparrow \mathrm{p}$-p38 & $(81)$ \\
\hline Aloesin & SKOV3 & $\downarrow$ p- JNK,$\downarrow$ p-p38 & (87) \\
\hline
\end{tabular}

$\mathrm{J}, \mathrm{TGF}-\beta$ signalling

\begin{tabular}{llll}
\hline Compound & Model & Target & $($ Refs.) \\
\hline Emodin & HeLa and SiHa & 侨GF- $\beta$ receptor II & $(61)$ \\
& HeLa & $\downarrow$ SMAD4, $\downarrow$ p- SMAD2, $\downarrow$ p-SMAD3 & $(61)$ \\
\hline
\end{tabular}

$\mathrm{K}$, Wnt signalling

\begin{tabular}{|c|c|c|c|}
\hline Compound & Model & Target & (Refs.) \\
\hline Aloe-emodin & JB6 CI 41-5a cell neoplastic model & $\begin{array}{l}\downarrow \text { EGF-induced phosphorylation of } \\
\text { GSK3 } \beta\end{array}$ & $(110)$ \\
\hline \multirow[t]{2}{*}{ Emodin } & HeLa & 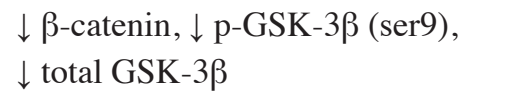 & $(61)$ \\
\hline & SW480 and SW620 & $\downarrow \beta$-catenin,$\downarrow$ TCF-4) & (69) \\
\hline Esculetin & SMMC-7721 & $\begin{array}{l}\downarrow \beta \text {-catenin, } \uparrow \mathrm{p}-\beta \text {-catenin } \\
(\text { Ser33/Ser37/Thr41) }\end{array}$ & $(113)$ \\
\hline \multirow[t]{3}{*}{ Aloesin } & $\begin{array}{l}\text { Super TCF NIH/3T3 (transfected with a Super } \\
\text { TCF reporter gene plasmid) }\end{array}$ & $\begin{array}{l}\uparrow \text { mRNA expression of Ccnd1, } \\
\text { Ctnnb1 and Axin } 2\end{array}$ & $(153)$ \\
\hline & Human colon cancer HCT-15 cell line & $\begin{array}{l}\uparrow \text { mRNA expression of c-MYC, } \\
\text { MMP-7, DKK } 1, \text { AXIN } 2 \text { and APC }\end{array}$ & $(153)$ \\
\hline & Human colon cancer RKO cell line & $\begin{array}{l}\uparrow \text { mRNA expression of c-MYC, } \\
\text { CCND1, GSK-3 } \beta, \text { AXIN2 and APC }\end{array}$ & $(153)$ \\
\hline
\end{tabular}

L, Immunomodulation (TNF- $\alpha-\mathrm{NF}-\kappa \mathrm{B}$ pathway) in cancer models

\begin{tabular}{|c|c|c|c|}
\hline Compound & Model & Target & (Refs.) \\
\hline \multirow[t]{3}{*}{ Emodin } & SW1990 and PANC-1 & $\downarrow N F-\kappa B$ & $(65,70,104)$ \\
\hline & Flagellin-stimulated HT-29 & 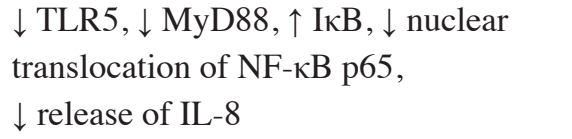 & $(172)$ \\
\hline & $\begin{array}{l}\text { U87MG hyaluronic acid-induced in vitro invasion } \\
\text { model }\end{array}$ & $\downarrow N F-\kappa B$ & $(120)$ \\
\hline Chrysophanol & MCF-7 and MDA-MB-231 & $\downarrow \mathrm{p}-\mathrm{I} \kappa \mathrm{B}, \downarrow \mathrm{p}-\mathrm{p} 65 \mathrm{NF}-\kappa \mathrm{B}$ & (74) \\
\hline \multirow[t]{2}{*}{ Aloin } & BGC-823 and HGC-27 & $\downarrow \mathrm{p}-\mathrm{I} \kappa \mathrm{B} \alpha, \downarrow \mathrm{p}-\mathrm{NF} \kappa \mathrm{B}$ & (78) \\
\hline & $\begin{array}{l}\text { Dimethylhydrazine-induced colon } \\
\text { carcinogenesis in Wistar rats }\end{array}$ & $\begin{array}{l}\downarrow \text { oxidative stress enzymes (glutathione } \\
\text { peroxidase, glutathione-S-transferase, } \\
\text { glutathione reductase, reduced } \\
\text { glutathione), } \downarrow \text { cyclooxygenase- } 2, \\
\downarrow \text { NOS } \downarrow \text { IL- } 6, \downarrow \text { PCNA, } \\
\downarrow \text { TNF- } \alpha \text { release }\end{array}$ & $(173)$ \\
\hline
\end{tabular}


Table I. Continued.

L, Immunomodulation (TNF- $\alpha-\mathrm{NF}-\kappa \mathrm{B}$ pathway) in cancer models

\begin{tabular}{|c|c|c|c|}
\hline Compound & Model & Target & (Refs.) \\
\hline \multirow[t]{2}{*}{ Esculetin } & PANC-1, MIAPaCa-2 and AsPC-1 & $\downarrow$ NF-кB, ІкB was unchanged & (88) \\
\hline & PC-3 & $\uparrow$ mRNA expression of TNFR 1 & (89) \\
\hline
\end{tabular}

$\uparrow$, stimulation or activation; $\downarrow$, suppression or inhibition; $\Delta \Psi \mathrm{m}$, outer mitochondrial membrane potential; ATM, ataxia telangiectasia mutated kinase; BAD, Bcl-2 associated agonist of cell death; BAX, Bcl-2-like protein 4; CDK, cyclin-dependent kinases; DR, death receptor; EGFR, epidermal growth factor receptor; ERK, extracellular signal-regulated kinase; FADD, Fas-associated protein with death domain; IkB, inhibitor of $\kappa \mathrm{B}$; JAK, Janus kinase; JNK, c-Jun N-terminal kinase; MAPK, mitogen-activated protein kinases; MCM2, minichromosome maintenance complex component 2; MEK, mitogen-activated ERK kinase; MMP, matrix metalloproteinase; mTOR, mammalian target of rapamycin; NF-кB, nuclear factor к-light-chain-enhancer of activated B cells; NO, nitric oxide; NOS, NO synthase; p-AKT, phosphorylated AKT; PARP, poly(ADP-ribose)polymerase; PI3K, phosphoinositide 3-kinase; RIP1, receptor interacting protein 1; ROS, reactive oxygen species; STAT, signal transducer and activator of transcription; TGF- $\beta$, transforming growth factor $\beta$.

Emodin has been previously indicated to activate the intrinsic mitochondrial pathway of apoptosis at all key stages in the human cervical cancer cell line HeLa $(60,61)$, the human hepatocarcinoma cell lines SMMC-7721 (62) and HepaRG (63), HepG2 (64) the human pancreatic cancer cell line SW1990 and its corresponding gemcitabine-resistant variant SW1990/Gem (65), the human lung adenocarcinoma cell line A549 $(66,67)$, the human neuroblastoma cell line IMR-32 (68) and the human colorectal carcinoma cell lines SW480 and SW620 (69). In addition, emodin treatment induced upregulation of Apaf-1 (60) and cyclophilin D expression (64) and reduced that of Survivin (67). It was indicated in tumour tissues from SW1990-inoculated nude mice that treatment with either emodin alone or emodin combined with gemcitabine reduced the $\mathrm{Bcl}-2 / \mathrm{BAX}$ ratio, while increasing caspase- 9 and caspase-3 activation and cytochrome $c$ release (70).

The anthraquinone chrysophanol also possess stimulatory effects on the intrinsic apoptotic pathway, including the suppression of Bcl-2 expression $(71,72)$ and the upregulation of pro-apoptotic proteins, including BAX $(71,72)$, caspase-3 (71,72), caspase-9 (72) and PARP-1 $(71,72)$. In addition, chrysophanol has also been reported to induce the loss of $\Delta \Psi \mathrm{m}(72-76)$ and to increase cytosolic $\mathrm{Ca}^{2+}$ concentrations $(73,74)$, cytochrome $c$ release $(73,75)$ and ROS generation (73,75-77). However, other studies reported that chrysophanol did not exert any effects on the protein expression levels of cleaved caspase-3 $(75,77)$, cleaved PARP (77), total protein levels of PARP (75), Apaf (75) or apoptosis-inducing factor (75). It was hypothesised that the reason for the caspase cascade not being activated despite apoptosis being initiated after chrysophanol treatment was due to a reduction in total ATP, meaning that cytochrome $c$ was not able to interact with Apaf-1 and pro-caspase-9 to form the apoptosome (71).

Aloin was able to markedly reduce the production of ROS in the human gastric cancer cell lines BGC-823 and HGC-27 (78), whilst increasing the cleavage of PARP and caspase-3 in a dose-dependent manner in HGC-27 cells (79). The protein levels of cleaved caspase- 3 and caspase- 9 were reported to be significantly increased in the human liver cancer cell lines HepG2 and Bel-7402 following aloin treatment (80). Aloin also significantly increased the protein expression levels of the intrinsic apoptosis pathway effectors BAK, BAX, p53 upregulated modulator of apoptosis, phorbol-12-myristate-13-acetate-induced protein 1, cleaved caspase-3 and caspase- 9 , which resulted in the loss of $\Delta \Psi \mathrm{m}$ and release of mitochondrial $\mathrm{Ca}^{2+}$ in A549 cells (81). The anti-apoptotic Bcl-xL gene was significantly reduced in response to aloin treatment of SW620 cells (82). Furthermore, aloin did not have any adverse effects on the mouse macrophage RAW264.7 cell line $(83,84)$, but lipopolysaccharide (LPS)-induced cleavage of caspase- 9 and caspase- 3 in RAW 264.7 cells was largely suppressed by aloin (85). Aloin was also documented to reduce hypoxia/reoxygenation-induced apoptosis of primary mouse hepatocytes in vitro by suppressing $\mathrm{BAX}$ and cleaved caspase- 3 protein levels, whilst increasing Bcl-2 expression (86), indicating that the aforementioned apoptotic effects were only selective on cancer cells.

Aloesin treatment of the ovarian cancer cell line SKOV3 led to the increased proteolytic cleavage of caspase-3, caspase-9 and PARP-1, as well as increased expression of BAX protein whilst decreasing that of $\mathrm{Bcl}-2$ protein in a dose-dependent manner (87). In addition, cleavage of caspase- 3 was stimulated by aloesin treatment in an ovarian cancer SKOV3 cell-derived xenograft model in athymic nude mice (87).

Treatment with esculetin reduced the level of $\Delta \Psi \mathrm{m}$, increased cytochrome $c$ release from mitochondria into the cytoplasm and reduced the $\mathrm{Bcl}-2 / \mathrm{BAX}$ ratio in addition to increasing caspase- 9 and caspase- 3 activity in different cancer models in vitro (88-91). The esculetin treatment group in an MGC-803 xenograft nude mouse model exhibited increased caspase-3 expression, as well as reduced Bcl-2 and nuclear $\mathrm{Ki}-67$ expression in vivo (90).

Umbelliferone effectively upregulated the expression of BAX whilst downregulating that of $\mathrm{Ki}-67$, minichromosome maintenance complex component 2 (MCM-2) and Bcl-2 proteins in three human renal cell carcinoma cell lines, 786-O, OS-RC-2 and ACHN (92). In addition, umbelliferone has also been indicated to enhance ROS production in the human laryngeal cancer cell line HEp-2 (93) and to reduce the $\Delta \Psi \mathrm{m}$ in the human oral carcinoma cell line KB (94). 
Treatment of the human liver cancer cell lines HepG2 and SK-Hep1 with isovitexin resulted in a dose-dependent cleavage of caspase-3 and PARP, an increase in BAX expression and cytochrome $c$ release into the cytoplasm, in addition to reducing $\mathrm{Bcl}-2$ expression (95). Isovitexin also triggered HeLa cell death through an oxidative stress-mediated signalling pathway and downregulating the protein expression of Bcl-2, whilst upregulating that of BAX and caspase-3 (96). In addition, isovitexin has been reported to increase caspase-3 and PARP cleavage in HepG2 cell tumour-bearing mice in vivo (95). By contrast, isovitexin was able to protect against LPS-induced oxidative damage by suppressing intracellular ROS generation in RAW 264.7 cells (97).

Intrinsic p53-dependent pathway of apoptosis initiation. The tumour suppressor p53 is able to induce various types of cell death, senescence, cell cycle arrest or subsequent DNA repair depending on the level of cellular damage. Mouse double minute 2 homolog (MDM2) constitutively binds to $\mathrm{p} 53$, leading to the ubiquitination and degradation of p53 when it is not required. DNA damage activates the ataxia telangiectasia mutated (ATM)/ataxia telangiectasia and Rad3-related kinases, which are able to phosphorylate and activate checkpoint kinase 1 (Chk1). Chk1 then phosphorylates p53 to disrupt MDM2 binding. p53 in turn upregulates the transcription of the cyclin-dependent kinase (CDK) inhibitor $\mathrm{p} 21$, induces the formation of a complex consisting of p53-induced death domain protein (PIDD1) and the receptor interacting protein (RIP)-associated ICH-1, CED-3-homologous protein with death domain, known as the PIDDosome, to activate caspase-2. In addition, p53 interacts with the Bcl-2 family of proteins and mitochondrial membranes to induce mitochondrial outer membrane permeabilisation and triggers the mitochondrial pathway of apoptosis (98).

All previous findings on the stimulation of p53 expression by Aloe compounds are listed in Table I and summarised in Fig. S1. A lyophilised A. vera extract was indicated to increase p53 mRNA expression in HepG2 cells in a time- and dose-dependent manner (49). In another study, aloe-emodin treatment induced p53 protein expression in tumour tissues from CD1 nude mice injected with U87MG cells (58). Emodin also induced apoptosis by activating the ROS-elicited ATM/p53/BAX signalling pathway in A549 cells (67). In addition, it was reported that emodin upregulated the $\mathrm{p} 53$ protein and phosphorylation of ATM, but did not alter the level of total ATM protein expression (67). Emodin also led to a direct increase in $\mathrm{p} 53$ and $\mathrm{p} 21$ protein expression in IMR-32 cells (68) and upregulated p53 expression in HepaRG cells (63), whereas aloin activated p53 phosphorylation on the Ser15, Thr18, Ser20 and Ser392 residues in A549 cells (81).

Extrinsic pathway of apoptosis initiation. The extrinsic pathway of apoptosis initiation via the death receptor (DR) signalling pathway is triggered by the activation of the death receptor family, which includes tumour necrosis factor (TNF) receptor 1 (TNFR1), Fas/CD95, DR3, DR4 and DR5, which results in the assembly of a caspase-activation platform called the death-inducing signalling complex. This platform recruits and activates caspase- 8 via the adaptor protein Fas-associated protein with death domain (FADD), which engages in the extrinsic apoptotic pathway (41).

Information available regarding the influence of Aloe-derived compounds on the extrinsic apoptosis pathway remains scarce (Table I). Aloe-emodin has been indicated to activate caspase-8 in U87MG xenograft tumour tissues in CD1 nude mice (58), whereas $\gamma$-irradiated aloe-emodin increased caspase- 8 protein expression in AGS cells (56).

Emodin treatment of HeLa cells led to upregulation of Fas, Fas ligand and FADD expression and simultaneously downregulated pro-caspase- 8 in a dose-dependent manner at both the mRNA and protein levels (60). Furthermore, the same treatment of HepaRG cells led to upregulation of cleaved caspase-8 levels (63).

The expression levels of DR5, RIP1 and RIP3 were revealed to be lower following treatment with chrysophanol compared with those in the untreated control in the human renal cell carcinoma cell line Caki-2 (77). Since simultaneous RIP1 and RIP3 expression allows normal cells to escape apoptosis and survive (41), chrysophanol may selectively prevent the survival of cancer cells. However, aloin treatment failed to induce activation of the extrinsic apoptosis pathway, as it did not affect the levels of cleaved caspase- 8 and -10 and CD95 in A549 cells (81). Esculetin was reported to increase the expression of caspase- 8 and cleaved caspase- 8 in PANC-1, MIAPaCa-2 and AsPC-1 cells (88) and in another study, it increased the mRNA expression levels of caspase- 8 in PC-3 cells (89).

Autophagy. Limited information is available on the effect of Aloe compounds on the autophagy process in cancer cells. However, aloe-emodin induced autophagy in MIAPaCa-2 cells by enhancing the conversion of microtubule-associated proteins $1 \mathrm{~A} / 1 \mathrm{~B}$ light chain 3B (LC3)-I to LC3-II in a dose-dependent manner (53). In addition, aloe-emodin treatment increased the number of endogenous LC3 puncta, LC3B-II and Beclin1 expression in A549 and NCI-H1299 cells (57). Isovitexin also induced autophagy in liver cancer cell lines, HepG2 and SK-Hep1, activating LC3, autophagy related (Atg)3, Atg5 and Beclin1 in a dose-dependent manner. Furthermore, isovitexin increased LC3II levels in tumour tissues from HepG2 cell tumour-bearing mice in vivo (95).

\section{Anticancer selectivity}

In terms of safety, investigation of the potential adverse effects of Aloe compounds on normal cells is of high importance, i.e. their associated cytotoxic effects should be selective for cancer cells. In previous studies, high selectivity and low toxicity of Aloe phytochemical compounds against normal cells have been reported.

Treatment with an aqueous whole-leaf extract of $A$. vera was indicated to selectively induce cell death in PC-3 cells but not in the normal human chondrocyte cell line C28/I2 (99). The $\mathrm{IC}_{50}$ value of the $A$. vera leaf extract on the MCF-7 cell line was $23 \mu \mathrm{g} / \mathrm{ml}$, whilst that for the non-tumour mouse embryonic fibroblast cell line NIH-3T3 was $332 \mu \mathrm{g} / \mathrm{ml}$ (100). This selectivity was comparable with that of the standard agent tamoxifen (100). 
Aloe polysaccharides (Chinese Academy of Sciences, Shanghai Institute of Materia Medica) elicited no significant cytotoxicity on the Madin-Darby canine kidney cell line at concentrations ranging from 20 to $640 \mu \mathrm{g} / \mathrm{ml}$ (31) and neither did Aloe polysaccharides on the cell viability of $\mathrm{HaCaT}$ cells following treatment at concentrations of 20, 40 and $80 \mu \mathrm{g} / \mathrm{ml}(101)$.

Aloe-emodin was reported to specifically inhibit MCF-10AT and MCF-7 cell growth, but did not exert any toxicity against the human non-tumorigenic spontaneously immortalised breast epithelial cell line MCF-10A (52). Furthermore, administration of aloe-emodin did not result in any cytotoxicity towards human peripheral mononuclear cells at all concentrations tested in the 0.001-100 $\mu \mathrm{M}$ range, whilst the $\mathrm{IC}_{50}$ values of aloe-emodin towards the lymphoblastic leukaemia cell line CCRF-CEM, the human colorectal carcinoma cell line HCT116, U87MG, the human breast adenocarcinoma MDA-MB-231 cell line and the tumorigenic human cell line 293T were in the 9.8-22.3 $\mu \mathrm{M}$ range (102). $\mathrm{IC}_{50}$ values were calculated to be in the range of 11.1-33.76 $\mu \mathrm{M}$ for the drug-resistant cell lines CEM/ADR5000, HCT116(p53 $\left.{ }^{-/}\right)$, U87MG $\triangle$ EGFR, MDA-MB- 231-BCRP clone 23 and HEK293-ABCB5 (102). Aloe-emodin did not confer any cytotoxic effects on neonatal rat ventricular myocytes at the concentration of $100 \mu \mathrm{M}$ (59). One approach to studying the potential anticancer and radio-protective effects of compounds is the measurement of radiolytic products following $\gamma$-irradiation (56). It was indicated that $\gamma$-irradiated aloe-emodin demonstrated increased anticancer activity in Moloney sarcoma virus-transformed BALB/3T3 mouse embryo fibroblast cells or in B16BL6 mouse skin melanoma cells, MCF-7 or THP-1 human monocytic leukaemia cells, but did not induce cytotoxicity in normal mouse embryonic fibroblast cells (BALB/3T3 clone A31) (56).

Emodin was reported to induce cytotoxicity in SW480 and SW620 cells, but not to a similar extent in normal human colon CCD 841 CoN (American Type Culture Collection ${ }^{\circledR}$ CRL-1790 ${ }^{\mathrm{TM}}$ ) cells (69). Emodin concentrations of $\leq 120 \mu \mathrm{g} / \mathrm{ml}$ did not exert any toxic effects in normal primary mouse fibroblasts (103). Emodin, gemcitabine and their combination provided high selectivity against SW1990 and PANC-1 cells compared with that in HPNE E6/E7 human pancreatic normal epithelial cells (104). A unique feature of emodin appeared to be the induction of cell death in microvascular endothelial cells in implanted pancreatic cancer tissues, whilst gemcitabine did not have any effect on pancreatic cancer-derived endothelial cells (104).

Chrysophanol did not affect the viability of the normal human prostatic epithelial cell line RWPE-1 at concentrations $\leq 5 \mu \mathrm{M}$, but was effective against benign prostatic hyperplasia cells (105). Furthermore, chrysophanol demonstrated selective activity against $\mathrm{J} 5$ cells with no toxicity against A10 normal rat myoblast cells (74). Furthermore, chrysophanol did not exert any cytotoxicity against MCF-12A normal human breast cells at concentrations of $\leq 100 \mu \mathrm{M}$, but did exhibit anticancer activity against BT-474 and MCF-7 cells (73).

Aloin at concentrations $\leq 1,000 \mu \mathrm{M}$ did not affect the viability of human umbilical cord vascular endothelial cells (HUVECs) $(106,107)$ and RAW264.7 macrophages were not affected by the aloin (barbaloin) at $\leq 500 \mu \mathrm{M}$ $(200 \mu \mathrm{g} / \mathrm{ml})(83-85)$.

Esculetin treatment at $\leq 1,700 \mu \mathrm{M}$ did not result in cell death of GES-1 normal human gastric epithelial cells, whilst anticancer activity against MGC-803, BGC-823 and HGC-27 cells was observed from a concentration of $560 \mu \mathrm{M}(90)$.

\section{Cell cycle regulation}

Cyclins are key regulators of the cell cycle that undergo a cycle of synthesis and degradation during each cell cycle, whereas the expression of cyclin-dependent kinases (CDK) remains constant but is activated in the presence of the appropriate regulatory cyclins. The levels of cyclin-CDK complexes, including D-CDK4/6, E-CDK2, A-CDK1/2 and B-CDK1, are essential for cell cycle progression $(108,109)$.

Treatment with crude whole-leaf A. arborescens extract induced p21 protein expression in the human epidermoid skin carcinoma cell line A431, as well as in MDA-MB-231 cells and the epithelial colorectal adenocarcinoma cell line Caco-2, whereas cyclin D1 expression was supressed in Caco-2 and MDA-MB-231 cells (51). The cell-cycle distribution was not affected in $\mathrm{HaCaT}$ cells after $48 \mathrm{~h}$ of treatment with the A. arborescens crude whole-leaf extract (51). However, proteomic analysis of $\mathrm{HaCaT}$ cells after exposure to $A$. arborescens whole-leaf extract revealed the expression of antiproliferative (78-kDa glucose-regulated protein 78 , prohibitin and stathmin) and antimicrobial (dermcidin) proteins (51).

Aloe-emodin treatment of U87MG cells resulted in cell cycle arrest at the $\mathrm{S}$ and $\mathrm{G} 2 / \mathrm{M}$ phases by increasing the expression of p53, p21 and reducing that of CDK2 (58). In another study, aloe-emodin administration led to an increase in the fraction of cells in the sub-G1 phase in MIAPaCa-2 cells (53). Aloe-emodin also induced cell cycle arrest at the G1 phase by reducing cyclin D1 transcription in EGF-induced transformed mouse skin epidermis cell line JB6 CI 41-5a in a dose-dependent manner (110). In addition, $\gamma$-irradiated aloe-emodin increased the population of cells in sub-G1 phase in a dose-dependent manner in AGS cells (56).

Cyclin D1 expression was decreased after treatment with either emodin or aloe-emodin in MCF7 cells (111). Treatment of IMR-32 cells with emodin led to a direct increase in p21 protein expression (68). Emodin treatment of HepaRG cells blocked cell cycle progression at the $\mathrm{S}$ and $\mathrm{G} 2 / \mathrm{M}$ phases by upregulating p21 and cyclin E, whilst downregulating cyclin A and CDK2 (63). Emodin also led to a reduction in mRNA and protein expression of c-Myc and cyclin-D1 in SW480 and SW620 cells (69). However, contradictory effects were observed in the human cervical cancer cell lines HeLa and $\mathrm{SiHa}$, where emodin blocked cell cycle progression, but simultaneously inhibited the expression of p15, p16, p $27^{\text {Kip1 }}$, CDK6, cyclin D1, p21 and peptidylprolyl cis/trans isomerase, NIMA-interacting 1 (61).

Chrysophanol was reported to induce S-phase arrest in A549 cells by decreasing the expression of cyclin D, CDK2 and thymidylate synthase protein (75). J5 cells exposed to chrysophanol also displayed S-phase arrest and necrotic cell death (74). Following chrysophanol treatment of MCF-7 and MDA-MB-231 cells, cell cycle arrest at the G1/S checkpoint 
occurred by inhibition of cyclin D1 and E expression and upregulation of p21 levels (71).

Aloin caused cell cycle arrest at the $\mathrm{S}$ and $\mathrm{G} 2$ phases in both BGC-823 and HGC-27 cells by reducing cyclin D1 protein expression, but did not alter the expression levels of cyclin E1 (78).

The levels of the S-G2/M-related proteins cyclin A, CDK2 and cyclin D1 were downregulated in SKOV3 cells following aloesin treatment in a dose-dependent manner (87). Treatment with aloesin resulted in increased levels of cyclin E, CDK2 and CDC25A in SK-HEP-1 cells (112).

Esculetin treatment significantly increased the percentage of PANC-1, MIAPaCa-2 and AsPC-1 cells in G1 phase with a concomitant reduction in the percentage of cells in the $\mathrm{S}$ and G2/M phases (88). Treatment of SMMC-7721 cells resulted in a significant reduction in the $\mathrm{mRNA}$ and protein levels of c-Myc and cyclin D1 (113). Esculetin caused cell cycle arrest in G1-phase in the human prostate cancer cell lines PC-3, DU145 and LNCaP (89). This appeared to be due to the increased expression of $\mathrm{p} 53, \mathrm{p} 21^{\mathrm{Cip} 1}$ and $\mathrm{p} 27^{\mathrm{Kip} 1}$, but reduced expression of CDK2, CDK4 and cyclin D1 in PC-3 cells (89).

Treatment of KB cells with umbelliferone induced G0/G1 phase arrest of the cell cycle (94). Umbelliferone induced G1 phase arrest in 786-O, OS-RC-2 and ACHN cells by downregulating the protein expression of Ki67, minichromosome maintenance complex component 2, CDK2, cyclin E1, CDK4 and cyclin D1 (92). Acemannan significantly enhanced the proliferation of mouse skin primary fibroblasts in a dose-dependent manner in vitro by promoting G1- to $\mathrm{S}$ phase progression (114). However, neither did acemannan induce cell apoptosis nor affect cyclin D1, cyclin E or CDK2/4 protein expression (114).

All effects of Aloe phytochemical compounds on cancer models in terms of cell cycle regulation are summarised in Table I and Fig. S2. Aloe-derived phytochemical compounds were able to block cell cycle progression in various cancer cell lines at different phases. However, the exact molecular effect on cell cycle regulators requires further evaluation for emodin and aloesin, since opposite effects were shown on p21 $(61,63,68)$ for emodin and on CDK2 $(87,112)$ for aloesin, which, at the same time, did not abrogate the final biological effect as cell cycle arrest.

\section{Cell signalling}

PI3K/AKT pathway. The phosphoinositide 3-kinase (PI3K)/AKT pathway is a potent signalling pathway that mediates cell proliferation and survival. Growth factors or hormones are able to activate tyrosine kinase receptors, which then activates PI3K toproduce phosphatidylinositol (3,4,5)-trisphosphate(PIP3) at the plasma membrane. PIP3 then recruits inactive cytosolic AKT, 3-phosphoinositide-dependent protein kinase 1 (PDK1) and mTOR to the membrane, where PDK1 and mTORC2 phosphorylate and activate AKT (115-117). Phosphorylated (p-) AKT levels may be used as a predictive factor of cancer progression (118). The levels of p-AKT were indicated to be elevated in hepatocellular carcinoma (53\%) compared with those in cirrhotic tissues $(12 \%)$ and were absent in normal liver samples $(\mathrm{P}<0.0001)$. Therefore, $\mathrm{p}-\mathrm{AKT}$ levels markedly differ between hepatic carcinoma and normal liver tissue (119).
After treatment with aloe-emodin, AKT phosphorylation was decreased in U87MG (58), A549 and NCI-H1299 cells (57). Aloe-emodin also inhibited EGF-induced phosphorylation of mitogen- and stress-activated kinase 1, PDK1 and AKT in a dose-dependent manner in the neoplastic JB6 CI 41-5a cell model (110).

In SMMC-7721 cells, emodin suppressed the activation of AKT, but did not decrease total AKT levels (62). Treatment with emodin in A549 cells also reduced the phosphorylation of AKT (66). In addition, pre-treatment of U87MG cells with emodin significantly decreased the phosphorylation of AKT (120). Oral administration of emodin effectively suppressed AKT phosphorylation in mice bearing U87MG tumours in vivo (120). However, no significant changes were observed in the ratios of $\mathrm{p}-\mathrm{PI} 3 \mathrm{~K} / \mathrm{PI} 3 \mathrm{~K}$ and $\mathrm{p}$-AKT/AKT in normal primary mouse fibroblasts after emodin treatment (103). In primary mouse fibroblasts derived from hypertrophic scar tissues in C57BL/6 mice, emodin treatment markedly inhibited PI3K and AKT activity (103).

Chrysophanol inhibited the phosphorylation of AKT, p70S6K and S6K in the BT-474 and MCF-7 cell lines, whilst endoplasmic reticulum stress-regulatory proteins, including double-stranded RNA-dependent protein kinase-like endoplasmic reticulum kinase, eukaryotic translation initiation factor $2 \alpha$, inositol-requiring enzyme-1 $\alpha$ and growth arrest and DNA damage-inducible protein 153 were activated (73). In addition, chrysophanol suppressed hypoxia-induced activation of PI3K/AKT signalling in HCT116 and SW480 cells by reducing the p-PI3K/PI3K and p-AKT/AKT ratios (121). Chrysophanol was also observed to suppress EGF-induced activation of EGFR, AKT, mTOR and p70S6K in the human colon carcinoma SNU-C5 cell line (122). However, treatment of JEG-3 cells with chrysophanol caused an increase in AKT and p70S6K phosphorylation in a dose- and time-dependent manner (76).

Aloin treatment led to downregulation of the phosphorylation and activation of Src, AKT, mTOR, p70S6K and S6K in a dose-dependent manner in BGC-823 and HGC-27 cells (78). After aloin exposure, phosphorylation of PI3K, AKT and mTOR was also significantly reduced in HepG2 and Bel-7402 cells in vitro and in orthotopic xenografts derived from HepG2 cells in vivo (80). Aloin was reported to inhibit the phosphorylation of AKT, mTOR, p70S6K, S6K and eukaryotic translation initiation factor 4E-binding protein 1 in HGC-27 and in recombinant human high-mobility group box 1 (rhHMGB1)-induced HGC-27 cells (79). However, in the non-cancerous LPS-stimulated model of RAW264.7 macrophages, aloin treatment led to downregulation of the phosphorylation levels of PI3K and AKT (84).

Esculetin markedly upregulated the expression levels of PTEN and suppressed the phosphorylation of AKT in PC-3 cells (89). The protein expression of insulin-like growth factor-1 (IGF-1), PI3K and AKT activation was reduced after esculetin treatment in SMMC-7721 cells (91). The protein expression of IGF-1 and the phosphorylation levels of PI3K and AKT were observed to be decreased after esculetin treatment in MGC-803 cells (90). Furthermore, in an MGC-803 nude mouse xenograft model, the levels of IGF-1 expression, as well as PI3K and AKT phosphorylation were decreased, whilst the expression levels of total PI3K and AKT remained unchanged following esculetin treatment (90). 
Treatment with umbelliferone led to a concentration-dependent reduction in the expression of the $\mathrm{p} 110 \gamma \mathrm{PI} 3 \mathrm{~K}$ subunit in the 786-O, OS-RC-2 and ACHN cell lines (92).

Acemannan was indicated to activate the phosphorylation of AKT, mTOR and p70S6K in primary mouse skin fibroblast cells in vitro, whilst activating mTOR in the wound tissue of an in vivo cutaneous wound model of BALB/c mice (114).

The effective suppression of the PI3K/AKT pathway mediated by the various phytochemical compounds isolated from the Aloe extracts and has been demonstrated (Table I and Fig. S3). However, certain controversial data regarding the effects of chrysophanol on the choriocarcinoma cell line remain, which require further investigation and verification.

Janus kinase $(J A K) /$ signal transducer and activator of transcription (STAT) pathway. The JAK/STAT signalling pathway is important for the regulation of angiogenesis, proliferation, migration, cell survival, haematopoiesis and development. This pathway has been demonstrated to be constantly active in malignant cells (123-125). The binding of an extracellular ligand to their respective receptors, including interleukins (ILs), vascular endothelial growth factor (VEGF) or interferons (IFN), leads to receptor oligo- or dimerisation, allowing the association and auto-transphosphorylation of intracellular JAKs. Activated JAKs then phosphorylate the intracellular domains of the receptors and STATs. Phosphorylated STATs subsequently dimerise and translocate into the nucleus, where they bind to enhancer sequences of target genes to activate transcription $(126,127)$.

The effects of Aloe extracts and associated phytochemical compounds on the JAK/STAT signalling pathway in cancer models are summarised in Table I and Fig. S3. The phosphorylation of STAT3 was suppressed by aloin treatment in BGC-823 and HGC-27 cells (78). Furthermore, treatment with aloin downregulated STAT3 phosphorylation in a dose-dependent manner but did not alter total STAT3 expression in SW620 cells. In the non-cancerous cell line RAW264.7, phosphorylation of STAT1, STAT3, JAK1 and JAK2 were not affected by aloin treatment (83). In addition, aloin did not affect STAT1 phosphorylation in HUVECs (128).

The relative protein expression levels of JAK1, JAK2 and STAT3 in HEp-2 cells in vitro and in HEp-2 xenograft tumours in nude mice in vivo were not changed after treatment with esculetin (93). The phosphorylation levels of JAK1, JAK2 and STAT3, by contrast, were significantly decreased in a dose-dependent manner (93).

Aloe polysaccharides also induced the downregulation of JAK2, p-JAK2, STAT-3 and p-STAT3 protein levels in an ulcerative colitis model using the HT-29 cell line in vitro and in a rat model of 2,4,6-trinitrobenzenesulfonic acid-induced colitis in vivo (129).

Mitogen-activated protein kinase (MAPK)/extracellular signal-regulated kinase (ERK) pathway. The MAPK/ERK signalling pathway regulates cellular signalling under both normal and pathological conditions. Dysregulation of this cascade results in the development of different types of cancer $(130,131)$. Binding of growth factors or cytokines, including EGF and hepatocyte growth factor, activates the corresponding receptors, which results in the recruitment of the adaptor protein growth factor receptor-bound protein 2 and the guanine nucleotide exchange protein factor son of sevenless to activate the Ras/Raf/MAPK/ERK1/2 cascade. This is followed by activation of target gene transcription. ERK1/2 is also able to activate the ribosomal protein S6 kinase A1 (p90RSK) in the cytosol, which then enters the nucleus and activates the transcription of target genes $(130,132)$. The MAPK/ERK signalling activation is essential for cell division, proliferation, differentiation and angiogenesis.

Treatment of proliferating $\mathrm{HaCaT}$ cells with crude whole-leaf extract isolated from A. arborescens resulted in reduction of ERK phosphorylation (51).

Emodin reduced the levels of p-ERK in HepG2 cells (64). In addition, in A549 cells, treatment with emodin resulted in decreased phosphorylation of ERK (66). Decreased levels of p-ERK1/2 after emodin treatment were also demonstrated on U87MG cells in vitro and in mice bearing U87MG tumours in vivo (120). By contrast, emodin treatment of SMMC-7721 cells increased the phosphorylation of ERK whilst not altering total ERK expression (62).

In prostate tissues of a rat model of benign prostatic hyperplasia, the upregulated phosphorylation of ERK was reversed by chrysophanol treatment, back to the levels similar to those in the corresponding normal controls (105). Chrysophanol was also reported to inhibit the phosphorylation of ERK1/2 in the BT-474 and MCF-7 cell lines (73). Chrysophanol was observed to suppress EGF-induced activation of ERK1/2 in SNU-C5 cells (122). However, treatment of JEG-3 cells with chrysophanol increased p-ERK1/2 levels after 5 min of exposure, in addition to increasing protein levels of p-p90RSK with the maximum peak reached at $5 \mathrm{~min}$, which was sustained for a period of $60 \mathrm{~min}(76)$.

Aloin was able to suppress the phosphorylation of ERK, p90RSK and the cyclic adenosine monophosphate response element-binding protein (CREB) in HGC-27 cells and in rhHMGB1-induced HGC-27 cells (79). By contrast, phosphorylation of ERK was not affected by aloin treatment of RAW264.7 cells (83). In addition, p-ERK1/2 and RUNX family transcription factor 2 protein levels in rat and human BM-MSCs were upregulated in the presence of aloin in a dose-dependent manner (133). Aloin suppressed D-galactose (D-gal)-induced ERK phosphorylation in the hippocampus of mice, whilst the total levels of ERK remain unchanged (134). Aloin treatment also downregulated polyphosphate (PolyP)-induced activation of ERK1/2 (106), whilst significantly inhibiting transforming growth factor- $\beta$ (TGF- $\beta$ )-induced protein (TGFBIp)-induced activation of ERK1/2 in HUVECs (107).

Aloesin dose-dependently decreased the phosphorylation levels of ERK and MAPK in SKOV3 cells (87), whilst the opposite effect was observed in non-cancerous cells. Aloesin treatment of HaCaT and RAW264.7 cells increased ERK phosphorylation (135). Isovitexin treatment inhibited the LPS-stimulated phosphorylation of ERK1/2 in RAW264.7 cells but did not have any effect on RAW264.7 cells in the absence of LPS stimulation (97). All of the effects of Aloe phytochemical compounds on the MAPK/ERK signalling pathway are summarised in Table I and Fig. S3. Most of the aforementioned compounds appeared to have exerted suppressive effects on the MAPK/ERK signalling pathway, with various controversial results for certain anthraquinones, 
including aloe-emodin, emodin and chrysophanol. This may be due to cancer-type specificity or inconsistent drug concentrations used, which require further verification. Furthermore, other MAPK signalling pathways, including JNK and p38, may also engage in crosstalk with the ERK signalling cascade, making it difficult to draw definitive conclusions on the final cell fate only based on the observation of the MAPK/ERK signalling pathway alone (136). Taking into account the physiological effects of all compounds mentioned, they may be considered bioactive in terms of their regulatory effects on cancer progression. In addition, in normal non-cancerous cells, most of these Aloe compounds did not have any effects, with the exception of the A. arborescens crude extract, aloin and aloesin.

MAPK/JNK/p38 pathway. Compared with the MAPK/ERK pathway, which is typically activated by mitogenic stimuli, the $\mathrm{MAPK} / \mathrm{JNK} / \mathrm{p} 38$ pathway is normally activated in response to stress signals and frequently observed to be deregulated in cancer. This signalling pathway is initiated following the activation of the respective receptors, followed by the triggering of megakaryoblastic leukaemia1/2/3-mitogen-activated protein kinase kinase (MEK)4/7-JNK1/2/3 or MEK1/4-MKK3/6-p38 cascades $(132,136,137)$.

Similar trends as those observed in the MAPK/ERK signalling pathway were also observed in the MAPK-JNK/p38 signalling pathway regarding the effects of Aloe phytochemical compounds. The phosphorylation of $\mathrm{p} 38$ was reported to be increased, whilst p-JNK was not changed in HUVECs following aloe-emodin treatment combined with photodynamic therapy, while no effect was obtained with aloe-emodin treatment alone (138).

Emodin induced the phosphorylation of p38, whilst mildly suppressing the phosphorylation of JNK in SMMC-7721 cells (62). In another study, emodin inhibited the activation of p38 MAPK in the lungs of Wistar rats exposed to cecal ligation and puncture (139).

Of note, phosphorylation of p38 and JNK was decreased in BT-474 cells but increased in MCF-7 cells in response to chrysophanol (73).

Aloin was indicated to significantly increase the levels of phosphorylated c-Jun and p38 in A549 cells after $48 \mathrm{~h}$ of treatment (81). Aloin also reduced LPS-induced phosphorylation of p38 in RAW264.7 cells (85), but phosphorylation levels of p38 and JNK were not affected by aloin treatment in the same cell line in another previous study in the absence of LPS (83). Aloin suppressed D-gal-induced p38 phosphorylation in the hippocampus of healthy mice but did not affect the total levels of p38 (134). In addition, aloin suppressed PolyP-enhanced vascular permeability in HUVECs whilst inhibiting the PolyP-induced upregulation of p38 phosphorylation (106). Aloin also significantly inhibited TGFBIp-induced activation of p38 MAPK in HUVECs, but did not exert any effects on p38 in HUVECs without TGFBIp induction (107). The mRNA levels of cyclooxygenase-2 (COX-2), p38 and JNK were not significantly changed in kidney tissues of healthy mice after aloin treatment. However, cecal ligation and puncture surgery resulted in an increase in COX-2, p38 and JNK mRNA expression, whilst post-surgery treatment with aloin resulted in the reversal of this effect (140).
Aloesin decreased the phosphorylation levels of JNK and p38 in SKOV3 cells (87). However, aloesin treatment of the non-cancerous cell lines HaCaT and RAW264.7 did not change the levels of p38 in neither their phosphorylated nor non-phosphorylated forms, but increased JNK phosphorylation (135).

Isovitexin treatment inhibited LPS-stimulated phosphorylation of JNK1/2 and p38 in RAW264.7 cells, but did not have any effect on RAW264.7 cells without LPS stimulation (97).

TGF- $\beta$ pathway. The TGF- $\beta$ signalling pathway serves a pivotal role in cells and has been reported to be involved in controlling embryogenesis, immunity, angiogenesis and cell motility and to exert anti-proliferative and pro-apoptotic effects $(141,142)$. However, an oncogenic role of this signalling pathway has been observed during the later stages of cancer development, exerting opposite functions in cancer cells compared with those in healthy cells $(143,144)$. The TGF- $\beta$ family of ligands normally bind to the constitutively active type II TGF- $\beta$ receptor, which results in the recruitment of type I receptors and the formation of receptor complexes. Activated type I receptor phosphorylates receptor-regulated SMADs, which in turn form a complex with SMAD4. This complex translocates into the nucleus and activates the TGF- $\beta$-responsive element to initiate gene transcription. SMAD6 and SMAD7 serve as inhibitors of this signalling pathway (145).

In primary mouse embryonic fibroblast cells, it was indicated that $A$. vera inner gel upregulated the expression of TGF- $\beta 1$ and basic fibroblast growth factor over the first $12 \mathrm{~h}$ of exposure (146). However, after $24 \mathrm{~h}$, their expression was downregulated (146). Topical application of A. vera gel onto cutaneous wounds of rats increased TGF- $\beta$ gene expression in the wound bed on days 4,7 and 14 compared with that in the untreated controls, ultimately accelerating the wound-healing process (147).

Aloe-emodin attenuated unilateral ureteral obstruction-induced renal interstitial fibrosis in vivo. The upregulation of the protein levels of TGF- $\beta 1$, collagen I, collagen IV and fibronectin in the renal tissues of mice following unilateral ureteral obstruction was significantly reversed after aloe-emodin treatment. The effects of aloe-emodin were comparable to those of the standard drug losartan. Application of aloe-emodin in vitro ameliorated renal interstitial fibrosis in TGF- $\beta 1$-induced HK- 2 cells by reducing the protein and mRNA expression levels of TGF- $\beta 1$, collagen I, collagen IV and fibronectin to basal values (32). Emodin downregulated the expression of TGF- $\beta$ receptor II in HeLa and SiHa cells. In addition, emodin downregulated SMAD4 and inhibited the phosphorylation of SMAD2 and SMAD3 in HeLa cells, without affecting the total SMAD2 and SMAD3 expression levels (61).

Aloesin treatment of a mouse wound excision model resulted in increased phosphorylation of both SMAD2 and SMAD3 in the wound tissue samples on day 7 post-injury without altering the expression of total SMAD2 and SMAD3 (135). Aloesin did not have any effect on the expression of SMAD7 (135). In addition, TGF- $\beta 1$ expression was increased in RAW264.7 cells following treatment with aloesin (135).

$A$. vera glucomannans was indicated to normalise the decreased levels of TGF- $\beta$ and IL-10 in the colon tissue in 
a dextran sodium sulphate (DSS)-induced colitis model, to levels comparable with those in the control group. However, $A$. vera glucomannans did not have any effect on TGF- $\beta$ levels in colon tissues of healthy animals, but promoted IL-10 production (148).

There is limited information available on the effect of Aloe phytochemical compounds on the TGF- $\beta$ signalling pathway in cancer models (Table I and Fig. S3). Instead, more pronounced effects were demonstrated on its regulation of tissue regeneration.

Wnt and Notch pathways. Under physiological conditions, $\beta$-catenin is constitutively phosphorylated by glycogen synthase kinase $3 \beta(\mathrm{GSK}-3 \beta)$ and casein kinase 1 (CK1) to be degraded by the complex consisting of axin, adenomatous polyposis coli (APC), GSK-3 $\beta$ and CK1. Upon activation of the Wnt cascade, $\beta$-catenin becomes stabilised and translocates into the nucleus to activate target gene transcription. The Wnt signalling pathway has been reported to regulate cell proliferation, survival and differentiation (149-151).

Peng et al (152) previously studied differentially expressed alternative splicing genes and their corresponding transcript variants in the human colorectal cancer cell line RKO after treatment with $A$. vera aqueous extract, isolated aloin and aloesin. Genes associated with activation of the Wnt pathway (co-activator, key factor and target genes) and inhibition of the Notch pathway (co-repressor genes) were indicated to be upregulated (152). However, the aqueous extract of $A$. vera and aloin were not able to directly activate the Wnt-signalling pathway in human colon cancer cell lines (153).

Aloe-emodin treatment was observed to inhibit EGF-induced phosphorylation of GSK-3 $\beta$ in a dose-dependent manner in a JB6 CI 41-5a cell neoplastic model (110).

Emodin downregulated the Wnt/ $\beta$-catenin signalling pathway in HeLa cells by inhibiting $\beta$-catenin and GSK-3 $\beta$ (ser9) phosphorylation and reducing total GSK-3 $\beta$ protein levels (61). In addition, emodin was able to significantly inhibit the expression of $\beta$-catenin (CTNNB1) and transcription factor (TCF)-4, also known as TCF7 like 2, in SW480 and SW620 cells (71).

Esculetin significantly reduced the mRNA and protein levels of $\beta$-catenin in SMMC-7721 cells. The total $\beta$-catenin protein levels were not evidently decreased but the phosphorylated $\beta$-catenin levels (Ser33/Ser37/Thr41) were increased (113).

Aloesin upregulated the protein expression of $\beta$-catenin in Super TCF (STCF) NIH/3T3 cells, which were transfected with the STCF reporter gene plasmid and in human colon cancer HCT-15 and RKO cells. Aloesin was also demonstrated to upregulate the mRNA expression of cyclin D1 (CCND1), CTNNB1 and AXIN2 in Super TCF NIH/3T3, c-MYC, matrix metalloproteinase (MMP)-7, dickkopf WNT signalling pathway inhibitor 1, AXIN2 and APC in HCT-15 cells and c-MYC, CCND1, GSK-3 $\beta$, AXIN2 and APC in RKO cells (153). These findings provided certain ambiguities on the possible carcinogenic effects of aloesin on the colon. However, no cell proliferation or cell cycle progression was observed after aloesin treatment in RKO cells. It is also noteworthy that the aforementioned gene expression data should be verified with protein expression and cascade activation assays.
A number of Aloe phytochemical compounds have demonstrated the ability to suppress the Wnt signalling pathway in cancer models (Fig. S3). However, certain discrepancies on the effects exerted by aloesin require further confirmation.

Suppression of the Notch pathway was also demonstrated for aloesin, aqueous extract of $A$. vera and aloin (153). After treatment with the aqueous extract of $A$. vera $(12.5 \mu \mathrm{g} / \mathrm{ml})$ and aloin $(1 \mu \mathrm{M})$, the mRNA level of NOTCH1, NOTCH2 and hes family bHLH transcription factor (HES) 5 in Super TCF NIH/3T3 cells were indicated to be significantly decreased. The aqueous extract of $A$. vera downregulated the mRNA expression of NOTCH1, jagged canonical Notch ligand 1 and HES1 in RKO cells and NOTCH1 and HES1 in HCT-15 cells. In addition, aloin downregulated the mRNA expression of NOTCH1 in RKO and HCT-15 cells, whilst aloesin downregulated the protein expression of NOTCH1 in RKO and HCT-15 cells (153).

\section{Angiogenesis}

Formation of new blood and lymph vessels is a major event during the development of all types of tissue, which is necessary for the delivery of oxygen, supply of nutrients and removal of metabolic waste products. In the case of tumorigenesis, increased angiogenesis is associated with the growth of the tumour and metastasis (154). A number of signalling pathways have been reported to be involved in angiogenesis stimulation, including PI3K/AKT, JAK/STAT and MAPK (155).

The number of newly-formed blood vessels was markedly reduced in the tumour tissue of L-1 sarcoma-bearing BALB/c mice after administration of the $A$. vera gel (156). By contrast, topical application of 1 and $2 \%$ A. vera cream activated angiogenesis, with its levels peaking on day 5 , in a full-thickness wound model in Sprague Dawley rats (157). A. vera extract treatment of mouse fibroblast cells for 24,48 and $72 \mathrm{~h}$ also slightly upregulated the expression of the VEGFA gene (158).

Matrige ${ }^{\circledR}$ HUVEC tubule formation assays were previously performed to study the effect of aloe-emodin alone and aloe-emodin combined with photodynamic therapy on capillary blood vessel structure formation. Aloe-emodin combined with photodynamic therapy reduced the number of branching points and tubules in addition to reducing the tubular length, whilst aloe-emodin alone exerted no significant effects on vessel formation. In addition, aloe-emodin alone did not confer any effects on VEGF expression or ERK, whilst aloe-emodin combined with photodynamic therapy significantly reduced the level of these two parameters (138). In a BALB/c mouse burn wound model, application of $100 \mathrm{mg}$ aloe-emodin ointment per mouse, at a concentration of 100 or $500 \mathrm{ng} / \mathrm{ml}$, increased VEGF expression in the burn wound tissues on days 1 and 3 (159).

Emodin treatment downregulated the angiogenesis index of endothelial cells isolated from implanted pancreatic cancer tissues in vitro, whilst also suppressing angiogenesis in orthotopically implanted pancreatic cancer tumours, as detected by tumour vascular imaging. In addition, emodin treatment significantly decreased the expression levels of endothelial markers CD31 and CD105, but downregulated the protein expression of VEGF. However, no effect was observed on VEGF receptor (VEGFR) expression in the orthotopically implanted 
pancreatic tumour tissues (104). In rats with jejunum injury, the JAK1/STAT3 signalling pathway in the jejunum tissue was markedly suppressed (160). However, after treatment with emodin, JAK1/STAT3 signalling activation was restored to levels comparable to those in the control group (160).

Chrysophanol significantly suppressed the expression of CD31, CD34 and angiogenin in tumour tissues from an A549 xenograft nude mouse model (73). Chrysophanol treatment of HCT116 and SW480 cells also led to a pronounced suppression of hypoxia-inducible factor $1 \alpha(\mathrm{HIF}-1 \alpha)$ protein expression downstream of hypoxia induction (121). The expression of CD31 and the protein levels of HIF-1 $\alpha$ and VEGF were reduced, whilst the protein level of vasohibin was increased by chrysophanol in a dose-dependent manner according to results from a HUVEC tubule-formation assay (72).

The expression of c-Myc and VEGF, which promote proliferation and angiogenesis, respectively, was significantly reduced in response to aloin treatment in SW620 cells. These in vitro results were confirmed in the SW620 xenograft nude mice model in vivo, where a tumour growth inhibition of $63 \%$ was observed on day 27 , with reduced numbers of CD31-positive cells and increased numbers of apoptotic cells (82). The relative protein expression of VEGF was also significantly reduced in HepG2 and Bel-7402 cells following aloin exposure. Furthermore, immunohistochemical staining of orthotopic xenograft HepG2 tumours in nude mice revealed reduced VEGF expression in the tumour tissues in vivo (80). Aloin also inhibited HUVEC cell proliferation, migration and tubule formation in vitro by downregulating VEGF-induced VEGFR2 phosphorylation at the Tyr1175 residue (82). Treatment with $400 \mu \mathrm{M}$ aloin did not alter the barrier integrity of HUVEC cell monolayers in vitro, but it suppressed the migration and adherence of neutrophils and inhibited leucocyte migration in a cecal ligation and puncture-induced septic mouse model in vivo (107).

In a previous study, aloesin was also observed to cause a dose-dependent stimulation of angiogenesis in the HUVEC tubule formation assay in vitro (135).

Acemannan upregulated VEGF expression in a dose-dependent manner in human deciduous dental pulp cells (161) and in primary human gingival fibroblasts (162).

Inhibitory effects of phytochemical compounds from Aloe on new vessel formation were observed. Although Aloe extracts have been indicated to demonstrate excellent wound healing properties, isolated phytochemical compounds do not appear to directly stimulate angiogenic mechanisms in normal cells, except for the A. vera extract and acemannan.

\section{Migration and invasion}

According to the TNM Classification of Malignant Tumours, late stages of cancer, namely stage III and IV, are defined as lymph node spreading or metastases (163), which reduces the probability of successful treatment. Cell migration and invasion are normal physiological processes that are important for development and regeneration (164). However, malignant cells use these processes for spreading across the body to form secondary tumours and to block or avoid 'stop'-signals (164).

CD82, also known as KAI-1, is a tetraspanin membrane protein that inhibits metastasis in human cancers $(165,166)$. It was observed that CD82 mRNA expression was increased by $\sim 4$-fold in PC-3 cells after treatment with aqueous whole-leaf extract of $A$. vera (99).

Key mesenchymal markers such as Snail, Slug and $\mathrm{N}$-cadherin were indicated to be downregulated following emodin treatment in HeLa cells (61). In addition, Lin et al (104) reported downregulation of MMP-2 and MMP-9 expression by emodin therapy in orthotopic pancreatic cancer tissues (104). Pre-treatment of four human glioma cell lines, U87MG, U373MG, U251MG and HS683, with $20 \mu \mathrm{M}$ emodin abolished hyaluronic acid-induced cell invasion and migration in vitro without inducing cellular toxicity, whilst MMP-9 and constitutive MMP-2 secretion were suppressed in a concentration-dependent manner (120). Oral administration of emodin also effectively suppressed MMP-9 expression in mice bearing U87MG tumours in vivo (120). In addition, in W480 and SW620 cells, emodin treatment resulted in the suppression of the expression of mesenchymal markers Snail and vimentin, MMP-2 and MMP-9 enzymes, but increased the expression of E-cadherin (69).

Chrysophanol inhibited the migration and invasion of A549 and H738 cells in a dose-dependent manner. The protein levels of MMP-2, MMP-9, N-cadherin and vimentin were all indicated to be decreased, whilst those of tissue inhibitors of metalloproteinases (TIMP) and E-cadherin were markedly increased by chrysophanol in a dose-dependent manner in A549 and $\mathrm{H} 738$ cells and in HUVECs (72). In addition, chrysophanol was able to significantly attenuate hypoxia-induced cell migration and invasion in the human colon cancer cell lines HCT116 and SW480 in vitro by downregulation of MMP-2 and MMP-9 and upregulation of TIMP-3. Furthermore, chrysophanol prevented epithelial-to-mesenchymal transition by reversing the supressed E-cadherin expression and reversing the upregulation of $\mathrm{N}$-cadherin and vimentin in hypoxia-induced cell migration and invasion models in HCT116 and SW480 cells. In an SW480 xenograft BALB/c nude mouse model, E-cadherin expression was indicated to be increased, whilst the expression of $\mathrm{N}$-cadherin and vimentin was decreased in tumour tissues after chrysophanol treatment (121).

Aloin suppressed the migration and invasion of BGC-823 and HGC-27 cells after $24 \mathrm{~h}$ of treatment by reducing the protein expression levels of MMP-2, MMP-9 and N-cadherin, whilst simultaneously upregulating E-cadherin expression (78). Aloin also reduced the number of invasive HepG2 and Bel-7402 cells according to results from Transwell and wound-healing assays by reducing MMP-9 expression (80).

Aloesin treatment inhibited the migration and invasion of SKOV3 cells, in addition to downregulating MMP-2 and MMP-9 protein expression in a dose-dependent manner. In an experimental model of pulmonary metastasis in immunodeficient nude mice, the number of metastatic lung colonies was significantly reduced by aloesin treatment (87).

\section{Inflammation and immunomodulation [TNF- $\alpha /$ nuclear factor $\kappa$-light-chain-enhancer of activated B cells (NF-кB) pathway]}

TNF is a double-edged sword due to conflicting reports on the effects of this signalling pathway, including proliferation, angiogenesis, interactions with the immune system, survival 
and apoptosis, which is dependent on the type of cancer in question (167). NF- $\kappa \mathrm{B}$ is a heterodimeric complex that is usually comprised of the p50 and p65 subunits, which is associated with its cytoplasmic inhibitor of $\kappa \mathrm{B}(\mathrm{I} \kappa \mathrm{B})$. After TNF- $\alpha$ binds to its receptor, TNF receptor (TNFR) superfamily member $1 \mathrm{~A}$ associated death domain binds to the intracellular domain of the receptor and recruits TNFR-associated factor (TRAF)2, which is a type of receptor-interacting protein. This complex then recruits and activates $\mathrm{I} \kappa \mathrm{B}$ kinase (IKK), which phosphorylates IкB and causes it to dissociate from $\mathrm{p} 65$, preventing $\mathrm{NF}-\kappa \mathrm{B}$ from degradation. This released $\mathrm{NF}-\kappa \mathrm{B}$ then translocates into the nucleus to activate target gene transcription $(168,169)$. However, other factors and receptors may activate the non-canonical TNF- $\alpha$ pathway without activating NF- $\kappa \mathrm{B}$ but will instead lead to cell death (see section 2) $(170,171)$.

Emodin downregulated the activation of $\mathrm{NF}-\kappa \mathrm{B}$ in a dose-dependent manner in SW1990 and PANC-1 cells $(65,70,104)$. In flagellin-stimulated HT-29 cells, it was revealed that emodin downregulated the expression of toll-like receptor (TLR)5 and myeloid differentiation primary response 88 (MyD88), upregulated the expression of $\mathrm{I} \kappa \mathrm{B}$, inhibited the nuclear translocation of $\mathrm{NF}-\kappa \mathrm{B}$ p 65 and reduced the production of IL-8 (172). Pre-treatment of U87MG cells with emodin also significantly reduced $\mathrm{NF}-\kappa \mathrm{B}$ activation in a hyaluronic acid-induced cell invasion model in vitro (120).

Chrysophanol treatment resulted in the downregulation of $\mathrm{I} \kappa \mathrm{B}$ and $\mathrm{p} 65 \mathrm{NF}-\kappa \mathrm{B}$ phosphorylation in MCF-7 and MDA-MB-231 cells (71).

The phosphorylation and subsequent activation of $\mathrm{I} \kappa \mathrm{B} \alpha$ and $\mathrm{NF}-\kappa \mathrm{B}$ was suppressed by aloin treatment in BGC-823 and HGC-27 cells (78). Aloin pre-treatment also ameliorated the damaging effects of dimethylhydrazine, a colon carcinogen, on Wistar rats through a protective mechanism that involved reducing the expression of oxidative stress enzymes glutathione peroxidase, glutathione-S-transferase, glutathione reductase and superoxide dismutase, reducing the expression of COX-2, inducible nitric oxide synthase (iNOS), IL-6 and proliferating cell nuclear antigen protein and inhibiting TNF- $\alpha$ release (173).

Esculetin treatment of PANC-1, MIAPaCa-2 and AsPC-1 cells significantly decreased the protein expression of $\mathrm{NF}-\kappa \mathrm{B}$ within 8-12 h without affecting that of its inhibitor $\mathrm{I} \kappa \mathrm{B}(88)$. After treating PC-3 cells with esculetin, the mRNA expression of TNFR1 was increased (89).

The described effects of the Aloe phytochemical compounds on the TNF- $\alpha$ pathway in cancer models are depicted in Fig. S3. However, Aloe phytochemical compounds also exerted immunomodulatory effects on normal cells in the absence of adverse effects in healthy animals.

Freeze-dried A. vera inner gel was indicated to significantly reverse Shigella flexneri- and LPS-induced TNF- $\alpha$ and IL-1 $\beta$ production to baseline levels in human peripheral blood leukocytes and THP-1 cells in vitro (174). The levels of TNF- $\alpha$ and IL-6 in the serum of Wistar Furth rats with second-degree burns were significantly decreased in the group treated topically with $A$. vera gel (175).

Treatment with aloe-emodin reduced the levels of inflammatory cytokine expression (IL-1 $\beta$, IL-6, TNF- $\alpha$, intercellular adhesion molecule 1 and vascular cell adhesion protein 1),
TLR4 and NF- $\kappa \mathrm{B}$ phosphorylation in a palmitic acid-induced inflammation model in the embryonic rat heart-derived cell line H9C2 (176).

Emodin treatment reduced the expression levels of TNF- $\alpha$, IL-6 and monocyte chemoattractant protein 1 (MCP-1) in primary mouse fibroblasts from the hypertrophic scar tissue in C57BL/6 mice. By contrast, in normal primary mouse fibroblasts, no significant changes were observed in the expression levels of TNF- $\alpha$, IL-6 or MCP-1 after emodin treatment (103). MCP-1 is secreted by numerous cell types, including monocytes, endothelial cells, smooth muscle cells and fibroblasts, as an initiator cytokine of the inflammatory cascade (177). Emodin was able to inhibit sepsis-induced secretion of pro-inflammatory cytokines IL- 6 and TNF- $\alpha$ into the serum of rats with jejunum cecal ligation and puncture (160) and lung cecal ligation and puncture (139). The protein expression of TLR5 and NF- $\kappa \mathrm{B}$ p65 was increased in the colon tissues of C57BL/6 mice following induced ulcerative colitis, which was in turn downregulated back to basal values after emodin treatment (172).

Aloin reduced PolyP- (106) and TGFBIp- (107) induced protein expression of TNF- $\alpha$ and IL-6, whilst downregulating the activation of NF- $\mathrm{B}$ in HUVECs. In aloin-treated mice following cecal ligation and puncture, the levels of plasma NO, TNF- $\alpha$, IL-6 and myeloperoxidase was normalised (140). Aloin significantly reversed cecal ligation and puncture induced iNOS protein expression, translocation and activation of $\mathrm{NF}-\kappa \mathrm{B}$ p 65 in the nucleus and $\mathrm{I} \kappa \mathrm{B}$ phosphorylation in kidney tissues of mice. However, aloin did not exert any adverse effects on NF- $\kappa$ B signalling in healthy mice (140). In LPS-treated C57BL/6 mice, aloin significantly alleviated lung injury and reduced the levels of TNF- $\alpha$ and iNOS production in the broncho-alveolar lavage fluid, but intravenous aloin administration did not result in any adverse effects in intact animals (128). In another study that was performed on a similar LPS-treated mouse model, aloin A suppressed LPS-induced phosphorylation of NF- $\mathrm{B}$ p65 and $\mathrm{I} \kappa \mathrm{B} \alpha$, whilst also suppressing the mRNA expression of TNF- $\alpha$, IL-1 $\beta$ and IL-6 in the lung tissues of mice. However, aloin A did not exert any toxic effects on lung tissues of normal mice or alter $\mathrm{p}-\mathrm{NF}-\kappa \mathrm{B}$ and $\mathrm{p}-\mathrm{I} \kappa \mathrm{B} \alpha$ levels in the lung tissue (84).

In LPS-stimulated RAW264.7 cells, the levels of pro-inflammatory cytokines and mediators, including TNF- $\alpha$, IL-1 $\beta$, IL-6, NO and iNOS, were inhibited by aloin, but no changes were observed in these mediators after aloin treatment without LPS stimulation (83-85).

Aloin was indicated to inhibit inflammatory responses in a hepatic ischemia-reperfusion model in C57BL/6 mice in vivo and in a hypoxia/re-oxygenation model in primary mouse hepatocytes in vitro by suppressing the NF- $\kappa \mathrm{B}$ signalling pathway. The protein expression levels of MyD88, TRAF6, $\mathrm{p}-\mathrm{IKK} \alpha / \beta$ and $\mathrm{p}-\mathrm{NF}-\kappa \mathrm{B}$ p65 in liver tissues or in primary hepatocytes returned to basal values after aloin treatment (86).

TNF- $\alpha$, IL-1 $\beta$ and IL-6 levels in hippocampal tissues in the D-gal-induced mouse model of cognitive dysfunction were decreased after aloin treatment. Furthermore, aloin suppressed D-gal-induced NF- $\kappa \mathrm{B}$ activation in the hippocampus (134). Aloin dose-dependently inhibited the expression of TRAF6, IKK $\alpha$, IKK $\beta$ and NF- $\mathrm{B}$ p 65 , whilst reducing the DNA-binding activity of $\mathrm{NF}-\kappa \mathrm{B}$ in an osteoclastogenesis model produced in 
RAW 264.7 cells in vitro (178). Treatment with aloesin reduced TNF- $\alpha$ levels in RAW264.7 cells (135).

Treatment with isovitexin inhibited LPS/D-gal-induced TNF- $\alpha$ expression and NF- $\kappa \mathrm{B} / \mathrm{I} \kappa \mathrm{B}$ phosphorylation in the serum samples and liver tissues of mice (179). In LPS-stimulated RAW264.7 cells, treatment with isovitexin inhibited the production of cytokines TNF- $\alpha$ and IL-6, suppressed iNOS and $\mathrm{COX}-2$ expression, blocked $\mathrm{I} \kappa \mathrm{B} \alpha$ phosphorylation and reduced the nuclear levels of $\mathrm{NF}-\kappa \mathrm{B}$ p65. Isovitexin did not demonstrate any adverse effects on the aforementioned mediators in RAW264.7 cells in the absence of LPS stimulation (97).

A. vera glucomannans reversed the increased levels of cytokines IL-6, TNF- $\alpha$ and IFN- $\gamma$ in colon tissues from a DSS-induced colitis mouse model group to levels similar to those in the control group. However, A. vera glucomannans did not mediate any effects on the cytokine levels in animals without this pathology (148).

Aloe polysaccharides reduced levels of IL-8 and IL-12 in TNF- $\alpha$-induced HaCaT cell lysates and cultured media. Furthermore, Aloe polysaccharides attenuated TNF- $\alpha$-induced expression of p $65 \mathrm{NF}-\kappa \mathrm{B}$ with simultaneous upregulation of $\mathrm{I} \kappa \mathrm{B} \alpha$ expression in $\mathrm{HaCaT}$ cells (101). Im et al (180) previously demonstrated a dose-dependent increase in TNF- $\alpha$ production, IL-1 $\beta$ and NO release by RAW267.4 cells cultured with protein-free modified Aloe polysaccharides (fraction G2E1D).

Acemannan significantly upregulated IL-6 and IL-8 mRNA expression in human primary gingival fibroblasts and increased IL-6 and IL-8 protein secretion (181). Pugh et al (182) reported that pharmaceutical-grade acemannan prepared using a series of alcohol precipitation and centrifugation steps contained chemically similar components, such as aloeride, that exhibit immunostimulatory activities (182). Aloeride was indicated to induce the expression of IL- $1 \beta$ and TNF- $\alpha$ mRNA in the human monocytes cell line THP-1 in vitro (182).

Acemannan induced the production of NO in normal chicken spleen cells and the chicken bone marrow-derived macrophage cell line HD11, which was most likely mediated through mannose receptors (183). Acemannan exhibited mitogenic activity at a concentration of $100 \mathrm{mg} / \mathrm{ml}$ when it was added to the culture of mouse total spleen cells (184). Acemannan stimulated IL-6 and TNF- $\alpha$ production and NO release by RAW267.4 cells (185).

Modulation of TLR signalling has also been documented to be a mechanism of Aloe extracts or phytochemical compounds. The expression of TLR-2 and TLR-6 mRNA was significantly suppressed by $A$. vera glucomannans treatment in normal mice. By contrast, the mRNA expression of TLR-9 was upregulated (148). The upregulated mRNA expression levels of TLR-2, TLR-4, TLR-6 and TLR-9 in the colon tissue of mice with DSS-induced colitis were attenuated by $A$. vera glucomannans (148). In response to LPS, the level of TLR-4 was upregulated in RAW264.7 macrophages, which was reversed by aloin A treatment (84).

\section{Recommendations for future applications}

Pure Aloe-derived compounds have highly selective anticancer properties but do not appear to produce any severe adverse effects in non-cancerous cell lines. In addition, therapies combining established anticancer agents with Aloe compounds are a possibility that should be investigated in future studies. In such combination therapies, the dosage of the standard chemotherapeutic drug in question may be reduced, which in turn may reduce adverse effects. Aloe phytochemicals may enhance the anticancer effects of standard therapeutic drugs through synergistic effects or by other mechanisms, including increasing drug concentrations in the tumour tissues. In a previous study by Shen et al (57), a synergistic effect between aloe-emodin and gemcitabine in A549 cells was confirmed. Emodin monotherapy or combination with gemcitabine promoted cell apoptosis of the human pancreatic cancer cell line SW1990 and its derived gemcitabine-resistant cell line SW1990/Gem (65). In addition, it was indicated that either emodin treatment alone or emodin combined with gemcitabine in pancreatic tumour tissues from SW1990 cell-inoculated nude mice reduced the Bcl-2/BAX ratio, increased caspase- 9 and caspase- 3 activation and cytochrome $c$ release, whilst reducing AKT (Ser473) levels (70). Isovitexin also inhibited cisplatin-induced renal inflammation by inhibiting TNF- $\alpha$, IL-1 $\beta$, IL-6 and malondialdehyde, ROS production and downregulation of $\mathrm{NF}-\kappa \mathrm{B}$ activation in kidney tissues (186).

\section{Conclusions}

The phytochemical components of different Aloe species have been documented for their healing effects in different diseases, particularly in cancer. Selected phytochemical compounds from different Aloe species have been reported to exert selective cytotoxic effects against cancer cells but not normal cells. The anticancer effects of some of these compounds have been demonstrated to be due to their influence on different signalling cascades and biochemical pathways. The limitation of the current review is that the mechanisms discussed are likely general downstream effects of Aloe compounds, despite most of the included studies having demonstrated their anticancer effect. Nevertheless, the data collected will be useful for further identification of direct targets. Hence, certain Aloe phytochemical compounds may be applied as highly efficient drugs to combat cancer, either alone or in combination with other anticancer drugs. In addition, plants from the Aloe genus remain to be a reservoir of bioactive compounds, which warrants further exploration.

\section{Acknowledgements}

Not applicable.

\section{Funding}

No funding was received.

\section{Availability of data and materials}

The datasets used and/or anlayzed during the current study are available from the corresponding author on reasonable request.

\section{Authors' contributions}

HS, JHH and CG made substantial contributions to manuscript conception and design, manuscript revision, critically 
analyzed literature data. HS performed supplementary figure drawing. Data authentication is not applicable. All authors have read and approved the final manuscript.

\section{Ethics approval and consent to participate}

Not applicable.

\section{Patient consent for publication}

Not applicable.

\section{Competing interests}

The authors declare that they have no competing interests.

\section{References}

1. Majumder R, Das CK and Mandal M: Lead bioactive compounds of Aloe vera as potential anticancer agent. Pharmacol Res 148: 104416, 2019.

2. Sánchez M, González-Burgos E, Iglesias I and Gómez-Serranillos MP: Pharmacological update properties of Aloe vera and its major active constituents. Molecules 25: 1324, 2020.

3. Cristiano G, Murillo-Amador B and De Lucia B: Propagation techniques and agronomic requirements for the cultivation of barbados aloe (Aloe vera (L.) Burm. F.) - A review. Front Plant Sci 7: 1410, 2016.

4. Pandey A and Singh S: Aloe vera: A Systematic Review of its Industrial and Ethno-Medicinal Efficacy. Int J Pharm Res Allied Sci 2016; 5: 21-33.

5. Svitina H, Swanepoel R, Rossouw J, Netshimbupfe H, Gouws C and Hamman J: Treatment of skin disorders with Aloe materials. Curr Pharm Des 25: 2208-2240, 2019.

6. Alinejad-Mofrad S, Foadoddini M, Saadatjoo SA and Shayesteh M: Improvement of glucose and lipid profile status with Aloe vera in pre-diabetic subjects: A randomized controlled-trial. J Diabetes Metab Disord 14: 22, 2015

7. Zhang Y, Liu W, Liu D, Zhao T and Tian H: Efficacy of Aloe vera supplementation on prediabetes and early non-treated diabetic patients: A systematic review and meta-analysis of randomized controlled trials. Nutrients 8: 388, 2016.

8. Anuradha A, Patil B and Asha VR: Evaluation of efficacy of Aloe vera in the treatment of oral submucous fibrosis - a clinical study. J Oral Pathol Med 46: 50-55, 2017.

9. Ipshita S, Kurian IG, Dileep P, Kumar S, Singh P and Pradeep AR: One percent alendronate and Aloe vera gel local host modulating agents in chronic periodontitis patients with class II furcation defects: A randomized, controlled clinical trial. J Investig Clin Dent 9: e12334, 2018

10. Kurian IG, Dileep P, Ipshita S and Pradeep AR: Comparative evaluation of subgingivally-delivered $1 \%$ metformin and Aloe vera gel in the treatment of intrabony defects in chronic periodontitis patients: A randomized, controlled clinical trial. J Investig Clin Dent 9: e12324, 2018.

11. Hong SW, Chun J, Park S, Lee HJ, Im JP and Kim JS: Aloe vera is effective and safe in short-term treatment of irritable bowel syndrome: A systematic review and meta-analysis. J Neurogastroenterol Motil 24: 528-535, 2018.

12. Lissoni P, Rovelli F, Brivio F, Zago R, Colciago M, Messina G, Mora A and Porro G: A randomized study of chemotherapy versus biochemotherapy with chemotherapy plus Aloe arborescens in patients with metastatic cancer. In Vivo 23: 171-175, 2009.

13. Cosmetic Ingredient Review Expert Panel: Final report on the safety assessment of Aloe andongensis extract, Aloe andongensis leaf juice, Aloe arborescens leaf extract, Aloe arborescens leaf juice, Aloe arborescens leaf protoplasts, Aloe barbadensis flower extract, Aloe barbadensis leaf, Aloe barbadensis leaf extract, Aloe barbadensis leaf juice, Aloe barbadensis leaf polysaccharides, Aloe barbadensis leaf water, Aloe ferox leaf extract, Aloe ferox leaf juice, and Aloe ferox leaf juice extract. Int J Toxicol 26 (Suppl 2): S1-S50, 2007.
14. Singab AN, El-Hefnawy HM, Esmat A, Gad HA and Nazeam JA: A systemic review on Aloe arborescens pharmacological profile: Biological activities and pilot clinical trials. Phytother Res 29: 1858-1867, 2015.

15. Beppu H, Shimpo K, Chihara T, Tamai I, Nomoto-Yamaji S, Ozaki S, Ito S and Kuzuya H: Inhibitory effects of aloe carboxypeptidase fraction on streptozotocin-induced enhancement of vascular permeability in the pancreatic islets. Phytomedicine 13 : 49-60, 2006.

16. Aloes: The Genus Aloe. Reynolds T (ed). CRC Press LLC, p408, 2004.

17. Cock IE: The genus Aloe: Phytochemistry and therapeutic uses including treatments for gastrointestinal conditions and chronic inflammation. Prog Drug Res 70: 179-235, 2015.

18. Pham DC, Shibu MA, Mahalakshmi B and Velmurugan BK: Effects of phytochemicals on cellular signaling: Reviewing their recent usage approaches. Crit Rev Food Sci Nutr 60: 3522-3546, 2020.

19. Sharifi-Rad J, Kamiloglu S, Yeskaliyeva B, Beyatli A, Alfred MA, Salehi B, Calina D, Docea AO, Imran M, Anil Kumar NV, et al: Pharmacological activities of psoralidin: A comprehensive review of the molecular mechanisms of action. Front Pharmacol 11: 571459, 2020.

20. Battino M, Giampieri F, Cianciosi D, Ansary J, Chen X, Zhang D, Gil E and Forbes-Hernández T: The roles of strawberry and honey phytochemicals on human health: A possible clue on the molecular mechanisms involved in the prevention of oxidative stress and inflammation. Phytomedicine 11: 153170, 2021.

21. Alikiaii B, Bagherniya M, Askari G, Johnston TP and Sahebkar A: The role of phytochemicals in sepsis: A mechanistic and therapeutic perspective. BioFactors 47: 19-40, 2021.

22. Nobili S, Lippi D, Witort E, Donnini M, Bausi L, Mini E and Capaccioli S: Natural compounds for cancer treatment and prevention. Pharmacol Res 59: 365-378, 2009.

23. Akhtar MF, Saleem A, Rasul A, Faran Ashraf Baig MM Bin-Jumah $M$ and Abdel Daim MM: Anticancer natural medicines: An overview of cell signaling and other targets of anticancer phytochemicals. Eur J Pharmacol 888: 173488, 2020.

24. Dagne E, Bisrat D, Viljoen A and van Wyk BE: Chemistry of aloe species. Cur Org Chem 4: 1055-1078, 2000.

25. Salehi B, Albayrak S, Antolak H, Kręgiel D, Pawlikowska E, Sharifi-Rad M, Uprety Y, Tsouh Fokou PV, Yousef Z, Amiruddin Zakaria Z, et al: Aloe genus plants: From farm to food applications and phytopharmacotherapy. Int J Mol Sci 19: 2843, 2018.

26. Mukherjee PK, Nema NK, Maity N, Mukherjee K and Harwansh RK: Phytochemical and therapeutic profile of Aloe vera. J Nat Remedies 14: 1-26, 2014

27. Nazeam JA, Gad HA, El-Hefnawy HM and Singab AB: Chromatographic separation and detection methods of Aloe arborescens Miller constituents: A systematic review. J Chromatogr B Analyt Technol Biomed Life Sci 1058: 57-67, 2017.

28. Babu SN and Noor A: Bioactive constituents of the genus Aloe and their potential therapeutic and pharmacological applications: A review. J Appl Pharm Sci 10: 133-145, 2020.

29. Arora MK, Sarup Y, Tomar R, Singh M and Kumar P: Amelioration of diabetes-induced diabetic nephropathy by Aloe vera: Implication of oxidative stress and hyperlipidemia. J Diet Suppl 16: 227-244, 2019.

30. Bala S, Chugh NA, Bansal SC, Garg ML and Koul A: Radiomodulatory effects of Aloe vera on hepatic and renal tissues of X-ray irradiated mice. Mutat Res 811: 1-15, 2018.

31. Sun Z, Yu C, Wang W, Yu G, Zhang T, Zhang L, Zhang J and Wei K: Aloe polysaccharides inhibit influenza a virus infection-a promising natural anti-flu drug. Front Microbiol 9: 2338, 2018.

32. Dou F, Liu Y, Liu L, Wang J, Sun T, Mu F, Guo Q, Guo C, Jia N, Liu W, et al: Aloe-emodin ameliorates renal fibrosis via inhibiting PI3K/Akt/mTOR signaling pathway in vivo and in vitro. Rejuvenation Res 22: 218-229, 2019.

33. Tewabe Y, Kefarge B, Belay H, Bisrat D, Hailu A and Asres K: Antileishmanial evaluation of the leaf latex of Aloe macrocarpa, aloin $\mathrm{A} / \mathrm{B}$, and its semisynthetic derivatives against two leishmania species. Evid Based Complement Alternat Med 2019: 4736181, 2019.

34. Choi JS, Islam MN, Ali MY, Kim EJ, Kim YM and Jung HA: Effects of C-glycosylation on anti-diabetic, anti-Alzheimer's disease and anti-inflammatory potential of apigenin. Food Chem Toxicol 64: 27-33, 2014 
35. Choo CY, Sulong NY, Man F and Wong TW: Vitexin and isovitexin from the leaves of Ficus deltoidea with in-vivo a-glucosidase inhibition. J Ethnopharmacol 142: 776-781, 2012.

36. Guimarães CC, Oliveira DD, Valdevite M, Saltoratto AL, Pereira SI, França Sde C, Pereira AM and Pereira PS: The glycosylated flavonoids vitexin, isovitexin, and quercetrin isolated from Serjania erecta Radlk (Sapindaceae) leaves protect PC12 cells against amyloid- $\beta 25-35$ peptide-induced toxicity. Food Chem Toxicol 86: 88-94, 2015.

37. Trinh HA, Dam VV, Banlunara W, Sangvanich P and Thunyakitpisal P: Acemannan induced bone regeneration in lateral sinus augmentation based on cone beam computed tomographic and histopathological evaluation. Case Rep Dent 2020 1675653,2020

38. Boonyagul S, Banlunara W, Sangvanich P and Thunyakitpisal P: Effect of acemannan, an extracted polysaccharide from Aloe vera, on BMSCs proliferation, differentiation, extracellular matrix synthesis, mineralization, and bone formation in a tooth extraction model. Odontology 102: 310-317, 2014.

39. Godoy DJD, Chokboribal J, Pauwels R, Banlunara W, Sangvanich P, Jaroenporn S and Thunyakitpisal P: Acemannan increased bone surface, bone volume, and bone density in a calvarial defect model in skeletally-mature rats. J Dent Sci 13 334-341, 2018.

40. Galluzzi L, Vitale I, Aaronson SA, Abrams JM, Adam D, Agostinis P, Alnemri ES, Altucci L, Amelio I, Andrews DW, et al: Molecular mechanisms of cell death: Recommendations of the nomenclature committee on cell death 2018. Cell Death Differ 25: 486-541, 2018.

41. Green DR and Llambi F: Cell death signaling. Cold Spring Harb Perspect Biol 7: a006080, 2015.

42. Chen Q, Kang J and Fu C: The independence of and associations among apoptosis, autophagy, and necrosis. Signal Transduct Target Ther 3: 18, 2018

43. Festjens N, Vanden Berghe T and Vandenabeele P: Necrosis, a well-orchestrated form of cell demise: Signalling cascades, important mediators and concomitant immune response. Biochim Biophys Acta 1757: 1371-1387, 2006.

44. Jin Z and El-Deiry WS: Overview of cell death signaling pathways. Cancer Biol Ther 4: 139-163, 2005.

45. Fox JL and MacFarlane M: Targeting cell death signalling in cancer: Minimising 'Collateral damage.' Br J Cancer 115: 5-11, 2016.

46. Redza-Dutordoir M and Averill-Bates DA: Activation of apoptosis signalling pathways by reactive oxygen species. Biochim Biophys Acta 1863: 2977-2992, 2016.

47. Kaufmann SH, Desnoyers S, Ottaviano Y, Davidson NE and Poirier GG: Specific proteolytic cleavage of poly(ADP-ribose) polymerase: An early marker of chemotherapy-induced apoptosis. Cancer Res 53: 3976-3985, 1993.

48. Chaitanya GV, Steven AJ and Babu PP: PARP-1 cleavage fragments: Signatures of cell-death proteases in neurodegeneration. Cell Commun Signal 8: 31, 2010.

49. Shalabi M, Khilo K, Zakaria MM, Elsebaei MG, Abdo W and Awadin W: Anticancer activity of Aloe vera and Calligonum comosum extracts separetely on hepatocellular carcinoma cells. Asian Pac J Trop Biomed 5: 375-381, 2015.

50. Yonehara A, Tanaka Y, Kulkeaw K, Era T, Nakanishi Y and Sugiyama D: Aloe vera extract suppresses proliferation of neuroblastoma cells in vitro. Anticancer Res 35: 4479-4486, 2015.

51. Di Luccia B, Manzo N, Vivo M, Galano E, Amoresano A, Crescenzi E, Pollice A, Tudisco R, Infascelli F and Calabrò V: A biochemical and cellular approach to explore the antiproliferative and prodifferentiative activity of Aloe arborescens leaf extract. Phytother Res 27: 1819-1828, 2013.

52. Jiang X, Liu Y, Zhang G, Lin S, Wu J, Yan X, Ma Y and Ma M: Aloe-emodin induces breast tumor cell apoptosis through upregulation of miR-15a/miR-16-1 that suppresses BCL2. Evid Based Complement Alternat Med 2020: 5108298, 2020.

53. Du Y, Zhang J, Tao Z, Wang C, Yan S, Zhang X and Huang M: Aloe emodin exerts potent anticancer effects in MIAPaCa- 2 and PANC-1 human pancreatic adenocarcinoma cell lines through activation of both apoptotic and autophagic pathways, sub-G1 cell cycle arrest and disruption of mitochondrial membrane potential $(\Delta \Psi \mathrm{m})$. J BUON 24: 746-753, 2019.

54. Cheng $\mathrm{C}$ and Dong W: Aloe-emodin induces endoplasmic reticulum stress-dependent apoptosis in colorectal cancer cells. Med Sci Monit 24: 6331-6339, 2018
55. Li Q, Wen J, Yu K, Shu Y, He W, Chu H, Zhang B and Ge C: Aloe-emodin induces apoptosis in human oral squamous cell carcinoma SCC15 cells. BMC Complement Altern Med 18: 296, 2018.

56. Byun EB, Kim HM, Sung NY, Yang MS, Kim WS, Choi D, Mushtaq S, Lee SS and Byun EH: Gamma irradiation of aloe-emodin induced structural modification and apoptosis through a ROS- and caspase-dependent mitochondrial pathway in stomach tumor cells. Int J Radiat Biol 94: 403-416, 2018.

57. Shen F, Ge C and Yuan P: Aloe-emodin induces autophagy and apoptotic cell death in non-small cell lung cancer cells via Akt/mTOR and MAPK signaling. Eur J Pharmacol 886: 173550 , 2020.

58. Arcella A, Oliva MA, Staffieri S, Sanchez M, Madonna M, Riozzi B, Esposito V, Giangaspero F and Frati L: Effects of aloe emodin on U87MG glioblastoma cell growth: In vitro and in vivo study. Environ Toxicol 33: 1160-1167, 2018.

59. Yu Y, Liu H, Yang D, He F, Yuan Y, Guo J, Hu J, Yu J, Yan X, Wang S and Du Z: Aloe-emodin attenuates myocardial infarction and apoptosis via up-regulating miR-133 expression. Pharmacol Res 146: 104315, 2019.

60. Yaoxian W, Hui Y, Yunyan Z, Yanqin L, Xin G and Xiaoke W: Emodin induces apoptosis of human cervical cancer hela cells via intrinsic mitochondrial and extrinsic death receptor pathway. Cancer Cell Int 13: 71, 2013.

61. Thacker PC and Karunagaran D: Curcumin and emodin down-regulate TGF- $\beta$ signaling pathway in human cervical cancer cells. PLoS One 10: e0120045, 2015.

62. Lin W, Zhong M, Yin H, Chen Y, Cao Q, Wang C and Ling C: Emodin induces hepatocellular carcinoma cell apoptosis through MAPK and PI3K/AKT signaling pathways in vitro and in vivo. Oncol Rep 36: 961-967, 2016.

63. Dong X, Ni B, Fu J, Yin X, You L, Leng X, Liang X and Ni J: Emodin induces apoptosis in human hepatocellular carcinoma HepaRG cells via the mitochondrial caspase-dependent pathway. Oncol Rep 40: 1985-1993, 2018.

64. Zhang L, He D, Li K, Liu H, Wang B, Zheng L and Li J: Emodin targets mitochondrial cyclophilin D to induce apoptosis in HepG2 cells. Biomed Pharmacother 90: 222-228, 2017.

65. Liu DL, Bu H, Li H, Chen H, Guo HC, Wang ZH, Tong HF, Ni ZL, Liu HB and Lin SZ: Emodin reverses gemcitabine resistance in pancreatic cancer cells via the mitochondrial apoptosis pathway in vitro. Int J Oncol 40: 1049-1057, 2012.

66. Su YT, Chang HL, Shyue SK and Hsu SL: Emodin induces apoptosis in human lung adenocarcinoma cells through a reactive oxygen species-dependent mitochondrial signaling pathway. Biochem Pharmacol 70: 229-241, 2005.

67. Lai JM, Chang JT, Wen CL and Hsu SL: Emodin induces a reactive oxygen species-dependent and ATM-p53-Bax mediated cytotoxicity in lung cancer cells. Eur J Pharmacol 623: 1-9, 2009

68. Huang FJ, Hsuuw YD and Chan WH: Characterization of apoptosis induced by emodin and related regulatory mechanisms in human neuroblastoma cells. Int J Mol Sci 14: 20139-20156, 2013.

69. Pooja T and Karunagaran D: Emodin suppresses Wnt signaling in human colorectal cancer cells SW480 and SW620. Eur J Pharmacol 742: 55-64, 2014.

70. Wei WT, Chen H, Ni ZL, Liu HB, Tong HF, Fan L, Liu A, Qiu MX, Liu DL, Guo HC, et al: Antitumor and apoptosis-promoting properties of emodin, an anthraquinone derivative from Rheum officinale Baill, against pancreatic cancer in mice via inhibition of Akt activation. Int J Oncol 39: 1381-1390, 2011.

71. Ren L, Li Z, Dai C, Zhao D, Wang Y, Ma C and Liu C: Chrysophanol inhibits proliferation and induces apoptosis through $\mathrm{NF}-\kappa \mathrm{B} /$ cyclin $\mathrm{D} 1$ and $\mathrm{NF}-\kappa \mathrm{B} / \mathrm{Bcl}-2$ signaling cascade in breast cancer cell lines. Mol Med Rep 17: 4376-4382, 2018.

72. Zhang J, Wang Q, Wang Q, Guo P, Wang Y, Xing Y, Zhang M, Liu F and Zeng Q: Chrysophanol exhibits anti-cancer activities in lung cancer cell through regulating ROS/HIF-1a/VEGF signaling pathway. Naunyn Schmiedebergs Arch Pharmacol 393: 469-480, 2020

73. Park S, Lim W and Song G: Chrysophanol selectively represses breast cancer cell growth by inducing reactive oxygen species production and endoplasmic reticulum stress via AKT and mitogen-activated protein kinase signal pathways. Toxicol Appl Pharmacol 360: 201-211, 2018.

74. Lu CC, Yang JS, Huang AC, Hsia TC, Chou ST, Kuo CL, Lu HF, Lee TH, Wood WG and Chung JG: Chrysophanol induces necrosis through the production of ROS and alteration of ATP levels in J5 human liver cancer cells. Mol Nutr Food Res 54: 967-976, 2010 
75. Ni CH, Yu CS, Lu HF, Yang JS, Huang HY, Chen PY, Wu SH, Ip SW, Chiang SY, Lin JG and Chung JG: Chrysophanol-induced cell death (necrosis) in human lung cancer A549 cells is mediated through increasing reactive oxygen species and decreasing the level of mitochondrial membrane potential. Environ Toxicol 29: 740-749, 2014.

76. Lim W, Yang C, Bazer FW and Song G: Chrysophanol induces apoptosis of choriocarcinoma through regulation of ROS and the AKT and ERK1/2 pathways. J Cell Physiol 232: 331-339, 2017.

77. Choi JS: Chrysophanic acid induces necrosis but not necroptosis in human renal cell carcinoma Caki-2 cells. J Cancer Prev 21: 81-87, 2016.

78. Wang Z, Tang T, Wang S, Cai T, Tao H, Zhang Q, Qi S and Qi Z: Aloin inhibits the proliferation and migration of gastric cancer cells by regulating NOX2-ROS-mediated pro-survival signal pathways. Drug Des Devel Ther 14: 145-155, 2020.

79. Tao H, Tang T, Wang S, Wang Z, Ma Y, Cai T, Cheng X, Qi S, Zhang Y and Qi Z: The molecular mechanisms of Aloin induce gastric cancer cells apoptosis by targeting High Mobility Group Box 1. Drug Des Devel Ther 13: 1221-1231, 2019.

80. Sun R, Zhai R, Ma C and Miao W: Combination of aloin and metformin enhances the antitumor effect by inhibiting the growth and invasion and inducing apoptosis and autophagy in hepatocellular carcinoma through PI3K/AKT/mTOR pathway. Cancer Med 9: 1141-1151, 2020.

81. Wan L, Zhang L, Fan K and Wang J: Aloin promotes A549 cell apoptosis via the reactive oxygen species-mitogen activated protein kinase signaling pathway and p53 phosphorylation. Mol Med Rep 16: 5759-5768, 2017.

82. Pan Q, Pan H, Lou H, Xu Y and Tian L: Inhibition of the angiogenesis and growth of Aloin in human colorectal cancer in vitro and in vivo. Cancer Cell Int 13: 69, 2013.

83. Ma Y, Tang T, Sheng L, Wang Z, Tao H, Zhang Q, Zhang Y and Qi Z: Aloin suppresses lipopolysaccharide-induced inflammation by inhibiting JAK1-STAT1/3 activation and ROS production in RAW264.7 cells. Int J Mol Med 42: 1925-1934, 2018.

84. Jiang K, Guo S, Yang C, Yang J, Chen Y, Shaukat A, Zhao G, Wu H and Deng G: Barbaloin protects against lipopolysaccharide (LPS)-induced acute lung injury by inhibiting the ROS-mediated $\mathrm{PI} 3 \mathrm{~K} / \mathrm{AKT}$ /NF- $\mathrm{B}$ pathway. Int Immunopharmacol 64: 140-150, 2018.

85. Luo X, Zhang H, Wei X, Shi M, Fan P, Xie W, Zhang Y and $\mathrm{Xu} \mathrm{N}$ : Aloin suppresses lipopolysaccharide-induced inflammatory response and apoptosis by inhibiting the activation of NF- $\kappa$ B. Molecules 23: 517, 2018

86. Du Y, Qian B, Gao L, Tan P, Chen H, Wang A, Zheng T, Pu S, Xia X and $\mathrm{Fu} \mathrm{W}$ : Aloin preconditioning attenuates hepatic ischemia/reperfusion injury via inhibiting TLR4/MyD88/NF- $\mathrm{BB}$ signal pathway in vivo and in vitro. Oxid Med Cell Longev 2019: 3765898, 2019.

87. Zhang LQ, Lv RW, Qu XD, Chen XJ, Lu HS and Wang Y: Aloesin suppresses cell growth and metastasis in ovarian cancer SKOV3 cells through the inhibition of the MAPK signaling pathway. Anal Cell Pathol (Amst) 2017: 8158254, 2017.

88. Arora R, Sawney S, Saini V, Steffi C, Tiwari M and Saluja D: Esculetin induces antiproliferative and apoptotic response in pancreatic cancer cells by directly binding to KEAP1. Mol Cancer 15: 64, 2016

89. Turkekul K, Colpan RD, Baykul T, Ozdemir MD and Erdogan S: Esculetin inhibits the survival of human prostate cancer cells by inducing apoptosis and arresting the cell cycle. J Cancer Prev 23 $10-17,2018$

90. Wang G, Lu M, Yao Y, Wang J and Li J: Esculetin exerts antitumor effect on human gastric cancer cells through IGF-1/PI3K/Akt signaling pathway. Eur J Pharmacol 814: 207-215, 2017.

91. Li J, Li S, Wang X and Wang H: Esculetin induces apoptosis of SMMC-7721 cells through IGF-1/PI3K/Akt-mediated mitochondrial pathways. Can J Physiol Pharmacol 95: 787-794, 2017.

92. Wang X, Huang S, Xin X, Ren Y, Weng G and Wang P: The antitumor activity of umbelliferone in human renal cell carcinoma via regulation of the $110 \gamma$ catalytic subunit of PI3K $\gamma$. Acta Pharm 69: 111-119, 2019.

93. Zhang G, Xu Y and Zhou HF: Esculetin inhibits proliferation, invasion, and migration of laryngeal cancer in vitro and in vivo by inhibiting Janus kinas (JAK)-signal transducer and activator of transcription-3 (STAT3) activation. Med Sci Monit 25: 7853-7863, 2019

94. Vijayalakshmi A and Sindhu G: Umbelliferone arrest cell cycle at G0/G1 phase and induces apoptosis in human oral carcinoma (KB) cells possibly via oxidative DNA damage. Biomed Pharmacother 92: 661-671, 2017
95. Lv SX and Qiao X: Isovitexin (IV) induces apoptosis and autophagy in liver cancer cells through endoplasmic reticulum stress. Biochem Biophys Res Commun 496: 1047-1054, 2018.

96. Girish TK, Kumar KA and Prasada Rao UJS: C-Glycosylated flavonoids from black gram husk: Protection against DNA and erythrocytes from oxidative damage and their cytotoxic effect on HeLa cells. Toxicol Rep 3: 652-663, 2016.

97. Lv H, Yu Z, Zheng Y, Wang L, Qin X, Cheng G and Ci X Isovitexin exerts anti-inflammatory and anti-oxidant activities on lipopolysaccharide-induced acute lung injury by inhibiting MAPK and NF- $\kappa \mathrm{B}$ and activating $\mathrm{HO}-1 / \mathrm{Nrf} 2$ pathways. Int J Biol Sci 12: 72-86, 2016.

98. Stegh AH: Targeting the p53 signaling pathway in cancer therapy - the promises, challenges and perils. Expert Opin Ther Targets 16: 67-83, 2012

99. Hosseini MS, Hosseini F, Ahmadi A, Mozafari M and Amjadi I: Antiproliferative activity of Hypericum perforatum, Achillea millefolium, and Aloe vera in interaction with the prostatic activity of CD82. Rep Biochem Mol Biol 8: 260-268, 2019.

100. Majumder R, Parida P, Paul S and Basak P: In vitro and in silico study of Aloe vera leaf extract against human breast cancer. Nat Prod Res 34: 2363-2366, 2020.

101. Leng H, Pu L, Xu L, Shi X, Ji J and Chen K: Effects of aloe polysaccharide, a polysaccharide extracted from Aloe vera, on TNF- $\alpha$-induced HaCaT cell proliferation and the underlying mechanism in psoriasis. Mol Med Rep 18: 3537-3543, 2018.

102. Ozenver N, Saeed M, Demirezer LO and Efferth T: Aloe-emodin as drug candidate for cancer therapy. Oncotarget 9: 17770-17796, 2018.

103. Liu C: Inhibition of mechanical stress-induced hypertrophic scar inflammation by emodin. Mol Med Rep 11: 4087-4092, 2015.

104. Lin SZ, Wei WT, Chen H, Chen KJ, Tong HF, Wang ZH, Ni ZL, Liu HB, Guo HC and Liu DL: Antitumor activity of emodin against pancreatic cancer depends on its dual role: Promotion of apoptosis and suppression of angiogenesis. PLoS One 7: e42146, 2012.

105. Youn DH, Park J, Kim HL, Jung Y, Kang J, Jeong MY, Sethi G, Seok Ahn K and Um JY: Chrysophanic acid reduces testosterone-induced benign prostatic hyperplasia in rats by suppressing $5 \alpha$-reductase and extracellular signal-regulated kinase. Oncotarget 8: 9500-9512, 2017.

106. Lee IC and Bae JS: Suppressive effects of aloin on polyphosphate-mediated vascular inflammatory responses. J Asian Nat Prod Res 23: 89-99, 2021.

107. Lee IC and Bae JS: Inhibitory effects of aloin on TGFBIp-mediated septic responses. J Asian Nat Prod Res 23: 189-203, 2021

108. Barnum KJ and O'Connell MJ: Cell cycle regulation by checkpoints. Methods Mol Biol 1170: 29-40, 2014

109. Poon RY: Cell cycle control: A system of interlinking oscillators. Methods Mol Biol 1342: 3-19, 2016.

110. Zhang J, Guo L, Zhang Q, Liu K and Dong Z: Aloe emodin suppresses EGF-induced neoplastic cell transformation by inhibiting the ERK/MSK1 and AKT/GSK3 $\beta$ signaling pathways. Mol Med Rep 18: 5215-5220, 2018.

111. Huang PH, Huang CY, Chen MC, Lee YT, Yue CH, Wang HY and Lin H: Emodin and Aloe-emodin suppress breast cancer cell proliferation through ER $\alpha$ inhibition. Evid Based Complement Alternat Med 2013: 376123, 2013.

112. Lee KY, Park JH, Chung MH, Park YI, Kim KW, Lee YJ and Lee SK: Aloesin up-regulates cyclin E/CDK2 kinase activity via inducing the protein levels of cyclin E, CDK2, and CDC25A in SK-HEP-1 cells. Biochem Mol Biol Int 41: 285-292, 1997.

113. Fan X, Du H, Sun Y, Jiang J, Wang Z, Yin W, Fan K and Li H: Suppression of the Wnt signaling pathway may contribute to the inhibition of proliferation of human hepatocellular carcinoma SMMC-7721 cells by esculetin. Oncol Lett 14: 1731-1736, 2017

114. Xing W, Guo W, Zou CH, Fu TT, Li XY, Zhu M, Qi JH, Song J, Dong $\mathrm{CH}, \mathrm{Li} \mathrm{Z}$, et al: Acemannan accelerates cell proliferation and skin wound healing through AKT/mTOR signaling pathway. J Dermatol Sci 79: 101-109, 2015.

115. Altomare DA and Testa JR: Perturbations of the AKT signaling pathway in human cancer. Oncogene 24: 7455-7464, 2005.

116. Manning BD and Toker A: AKT/PKB Signaling: Navigating the network. Cell 169: 381-405, 2017.

117. Madhunapantula SV, Mosca PJ and Robertson GP: The Akt signaling pathway: An emerging therapeutic target in malignant melanoma. Cancer Biol Ther 12: 1032-1049, 2011 
118. Nakanishi K, Sakamoto M, Yamasaki S, Todo S and Hirohashi S: Akt phosphorylation is a risk factor for early disease recurrence and poor prognosis in hepatocellular carcinoma. Cancer 103: 307-312, 2005.

119. Kunter I, Erdal E, Nart D, Yilmaz F, Karademir S, Sagol O and Atabey N: Active form of AKT controls cell proliferation and response to apoptosis in hepatocellular carcinoma. Oncol Rep 31: 573-580, 2014.

120. Kim MS, Park MJ, Kim SJ, Lee CH, Yoo H, Shin SH, Song ES and Lee SH: Emodin suppresses hyaluronic acid-induced MMP-9 secretion and invasion of glioma cells. Int J Oncol 27: 839-846, 2005.

121. Deng M, Xue YJ, Xu LR, Wang QW, Wei J, Ke XQ, Wang JC and Chen XD: Chrysophanol suppresses hypoxia-induced epithelial-mesenchymal transition in colorectal cancer cells. Anat Rec (Hoboken) 302: 1561-1570, 2019.

122. Lee MS, Cha EY, Sul JY, Song IS and Kim JY: Chrysophanic acid blocks proliferation of colon cancer cells by inhibiting EGFR/mTOR pathway. Phytother Res 25: 833-837, 2011.

123. Pencik J, Pham HT, Schmoellerl J, Javaheri T, Schlederer M, Culig Z, Merkel O, Moriggl R, Grebien F and Kenner L: JAK-STAT signaling in cancer: From cytokines to non-coding genome. Cytokine 87: 26-36, 2016.

124. Verhoeven Y, Tilborghs S, Jacobs J, De Waele J, Quatannens D, Deben C, Prenen H, Pauwels P, Trinh XB, Wouters A, et al: The potential and controversy of targeting STAT family members in cancer. Semin Cancer Biol 60: 41-56, 2020.

125. Hin Tang JJ, Hao Thng DK, Lim JJ and Toh TB: JAK/STAT signaling in hepatocellular carcinoma. Hepat Oncol 7: HEP18, 2020 .

126. Harrison DA: The Jak/STAT pathway. Cold Spring Harb Perspect Biol 4: a011205, 2012.

127. Kiu H and Nicholson SE: Biology and significance of the JAK/STAT signalling pathways. Growth Factors 30: 88-106, 2012

128. Lee W, Yang S, Lee C, Park EK, Kim KM, Ku SK and Bae JS Aloin reduces inflammatory gene iNOS via inhibition activity and p-STAT-1 and NF- $\kappa$ B. Food Chem Toxicol 126: 67-71, 2019.

129. Lin H, Honglang L, Weifeng L, Junmin C, Jiantao Y and Junjing G: The mechanism of alopolysaccharide protecting ulceralive colitis. Biomed Pharmacother 88: 145-150, 2017.

130. Guo YJ, Pan WW, Liu SB, Shen ZF, Xu Y and Hu LL: ERK/MAPK signalling pathway and tumorigenesis. Exp Ther Med 19: 1997-2007, 2020.

131. McCain J: The MAPK (ERK) pathway: Investigational combinations for the treatment of BRAF- mutated metastatic melanoma. P T 38: 96-108, 2013.

132.Zhang W and Liu HT: MAPK signal pathways in the regulation of cell proliferation in mammalian cells. Cell Res 12: 9-18, 2002.

133. Li P, Kong J, Chen Z, Huang S, Lv G, Wei B, Wei J, Jing K, Quan J and Chu J: Aloin promotes osteogenesis of bone-marrow-derived mesenchymal stem cells via the ERK1/2-dependent Runx2 signaling pathway. J Nat Med 73: 104-113, 2019

134. Zhong J, Wang F, Wang Z, Shen C, Zheng Y, Ma F, Zhu T, Chen L, Tang $\mathrm{Q}$ and Zhu J: Aloin attenuates cognitive impairment and inflammation induced by d-galactose via down-regulating ERK, p38 and NF- $\kappa \mathrm{B}$ signaling pathway. Int Immunopharmacol 72 : 48-54, 2019

135. Wahedi HM, Jeong M, Chae JK, Do SG, Yoon H and Kim SY: Aloesin from Aloe vera accelerates skin wound healing by modulating MAPK/Rho and Smad signaling pathways in vitro and in vivo. Phytomedicine 28: 19-26, 2017.

136. Wagner EF and Nebreda ÁR: Signal integration by JNK and p38 MAPK pathways in cancer development. Nat Rev Cancer 9 537-549, 2009.

137. Zhou YY, Li Y, Jiang WQ and Zhou LF: MAPK/JNK signalling: A potential autophagy regulation pathway. Biosci Rep 35: e00199, 2015.

138. Chen Q, Li KT, Tian S, Yu TH, Yu LH, Lin HD and Bai DQ Photodynamic therapy mediated by aloe-emodin inhibited angiogenesis and cell metastasis through activating MAPK signaling pathway on HUVECs. Technol Cancer Res Treat 17: $1533033818785512,2018$.

139. Yin JT, Wan B, Liu DD, Wan SX, Fu HY, Wan Y, Zhang H and Chen Y: Emodin alleviates lung injury in rats with sepsis. J Surg Res 202: 308-314, 2016.

140. Lee W, Jeong GS, Baek MC, Ku SK and Bae JS: Renal protective effects of aloin in a mouse model of sepsis. Food Chem Toxicol 132: 110651, 2019.
141. Penn JW, Grobbelaar AO and Rolfe KJ: The role of the TGF- $\beta$ family in wound healing, burns and scarring: A review. Int J Burns Trauma 2: 18-28, 2012.

142. Barrientos S, Stojadinovic O, Golinko MS, Brem H and Tomic-Canic M: Growth factors and cytokines in wound healing. Wound Repair Regen 16: 585-601, 2008.

143. Creeden J, Ong S, Gillman C, Atkinson R, Stanbery L, Dworkin L and Nemunaitis J: The Role of TGF $\beta$ in Clinical Cancer Response. Clin Oncol Res 2020; 1-8, 2020.

144. Chaudhury A and Howe PH: The tale of transforming growth factor-beta (TGFbeta) signaling: A soigné enigma. IUBMB Life 61: 929-939, 2009.

145. Calone I and Souchelnytskyi S: Inhibition of TGF $\beta$ signaling and its implications in anticancer treatments. Exp Oncol 34: 9-16, 2012

146. Hormozi M, Assaei R and Boroujeni MB: The effect of Aloe vera on the expression of wound healing factors (TGF $\beta 1$ and bFGF) in mouse embryonic fibroblast cell: In vitro study. Biomed Pharmacother 88: 610-616, 2017.

147. Takzaree N, Hadjiakhondi A, Hassanzadeh G, Rouini MR, Manayi A and Zolbin MM: Transforming growth factor- $\beta$ (TGF- $\beta$ ) activation in cutaneous wounds after topical application of Aloe vera gel. Can J Physiol Pharmacol 94: 1285-1290, 2016.

148. Zhang LJ, Huang XJ, Shi XD, Chen HH, Cui SW and Nie SP: Protective effect of three glucomannans from different plants against DSS induced colitis in female BALB/c mice. Food Funct 10: 1928-1939, 2019.

149. Klaus A and Birchmeier W: Wnt signalling and its impact on development and cancer. Nat Rev Cancer 8: 387-398, 2008

150. MacDonald BT, Tamai K and He X: Wnt/beta-catenin signaling: Components, mechanisms, and diseases. Dev Cell 17: 9-26, 2009.

151. Komiya $\mathrm{Y}$ and Habas R: Wnt signal transduction pathways. Organogenesis 4: 68-75, 2008.

152. Peng C, Zhang W, Shen X, Yuan Y, Li Y, Zhang W and Yao M: Post-transcriptional regulation activity through alternative splicing involved in the effects of Aloe vera on the Wnt/ $\beta$-catenin and Notch pathways in colorectal cancer cells. J Pharmacol Sci 143: 148-155, 2020

153. Peng C, Zhang W, Dai C, Li W, Shen X, Yuan Y, Yan L, Zhang W and Yao M: Study of the aqueous extract of Aloe vera and its two active components on the Wnt/ $\beta$-catenin and Notch signaling pathways in colorectal cancer cells. J Ethnopharmacol 243: $112092,2019$.

154. Nishida N, Yano H, Nishida T, Kamura T and Kojiro M: Angiogenesis in cancer. Vasc Health Risk Manag 2: 213-219, 2006.

155. Kerbel RS: Tumor angiogenesis. N Engl J Med 358: 2039-2049, 2008.

156. Kocik J, Bałan BJ,Zdanowski R, Jung L, Skopińska-Rózewska E and Skopiński P: Feeding mice with Aloe vera gel diminishes L-1 sarcoma-induced early neovascular response and tumor growth. Cent Eur J Immunol 39: 14-18, 2014.

157. Prakoso YA and Kurniasih: The effects of Aloe vera cream on the expression of $\mathrm{CD}^{+}$and $\mathrm{CD}^{+}$lymphocytes in skin wound healing. J Trop Med 2018: 6218303, 2018.

158. Negahdari S, Galehdari H, Kesmati M, Rezaie A and Shariati G: Wound healing activity of extracts and formulations of Aloe vera, henna, Adiantum capillus-veneris, and myrrh on mouse dermal fibroblast cells. Int J Prev Med 8: 18, 2017.

159. Lin LX, Wang P, Wang YT, Huang Y, Jiang L and Wang XM: Aloe vera and Vitis vinifera improve wound healing in an in vivo rat burn wound model. Mol Med Rep 13: 1070-1076, 2016.

160. Chen YK, Xu YK, Zhang H, Yin JT, Fan X, Liu DD, Fu HY and Wan B: Emodin alleviates jejunum injury in rats with sepsis by inhibiting inflammation response. Biomed Pharmacother 84: 1001-1007, 2016

161. Songsiripradubboon S, Kladkaew S, Trairatvorakul C, Sangvanich $\mathrm{P}$, Soontornvipart K, Banlunara W and Thunyakitpisal P: Stimulation of dentin regeneration by using acemannan in teeth with lipopolysaccharide-induced pulp inflammation. J Endod 43: 1097-1103, 2017.

162. Jettanacheawchankit $S$, Sasithanasate $S$, Sangvanich $P$, Banlunara W and Thunyakitpisal P: Acemannan stimulates gingival fibroblast proliferation; expressions of keratinocyte growth factor-1, vascular endothelial growth factor, and type I collagen; and wound healing. J Pharmacol Sci 109: 525-531, 2009.

163. RosenRDadSapraA:TNMClassification.In:StatPearls-[Internet]. StatPearls Publishing, Treasure Island,FL, 2021.https://www.ncbi. nlm.nih.gov/books/NBK553187/. Accessed February 23, 2021. 
164. Krakhmal NV, Zavyalova MV, Denisov EV, Vtorushin SV and Perelmuter VM: Cancer invasion: Patterns and mechanisms. Acta Naturae 7: 17-28, 2015

165. Feng J, Huang C, Wren JD, Wang DW, Yan J, Zhang J, Sun Y, Han X and Zhang XA: Tetraspanin CD82: A suppressor of solid tumors and a modulator of membrane heterogeneity. Cancer Metastasis Rev 34: 619-633, 2015.

166. Prabhu VV and Devaraj SN: KAI1/CD82, metastasis suppressor gene as a therapeutic target for non-small-cell lung carcinoma. J Environ Pathol Toxicol Oncol 36: 269-275, 2017.

167. Wang X and Lin Y: Tumor necrosis factor and cancer, buddies or foes? Acta Pharmacol Sin 29: 1275-1288, 2008.

168. van Horssen R, Ten Hagen TL and Eggermont AM: TNF-alpha in cancer treatment: Molecular insights, antitumor effects, and clinical utility. Oncologist 11: 397-408, 2006.

169. Montfort A, Colacios C, Levade T, Andrieu-Abadie N, Meyer N and Ségui B: The TNF paradox in cancer progression and immunotherapy. Front Immunol 10: 1818, 2019.

170. Katsuyama K, Shichiri M, Marumo F and Hirata Y: NO inhibits cytokine-induced iNOS expression and NF-kappaB activation by interfering with phosphorylation and degradation of IkappaB-alpha. Arterioscler Thromb Vasc Biol 18: 1796-1802, 1998.

171. Holbrook J, Lara-Reyna S, Jarosz-Griffiths H and McDermott M: Tumour necrosis factor signalling in health and disease. F1000Res 8: F1000 Faculty Rev-111, 2019.

172. Luo S, Deng X, Liu Q, Pan Z, Zhao Z, Zhou L and Luo X Emodin ameliorates ulcerative colitis by the flagellin-TLR5 dependent pathway in mice. Int Immunopharmacol 59: 269-275, 2018.

173. Hamiza OO, Rehman MU, Khan R, Tahir M, Khan AQ, Lateef A and Sultana S: Chemopreventive effects of aloin against 1,2-dimethylhydrazine-induced preneoplastic lesions in the colon of Wistar rats. Hum Exp Toxicol 33: 148-163, 2014.

174. Habeeb F, Stables G, Bradbury F, Nong S, Cameron P, Plevin R and Ferro VA: The inner gel component of Aloe vera suppresses bacterial-induced pro-inflammatory cytokines from human immune cells. Methods 42: 388-393, 2007.

175. Duansak D, Somboonwong J and Patumraj S: Effects of Aloe vera on leukocyte adhesion and TNF-alpha and IL-6 levels in burn wounded rats. Clin Hemorheol Microcirc 29: 239-246, 2003

176. Chen Y, Feng B, Yuan Y, Hu J, Zhao W, Jiang H, Li W, Fan Z and Du Z: Aloe emodin reduces cardiac inflammation induced by a high-fat diet through the TLR4 signaling pathway. Mediators Inflamm 2020: 6318520, 2020.
177. Deshmane SL, Kremlev S, Amini S and Sawaya BE: Monocyte chemoattractant protein-1 (MCP-1): An overview. J Interf Cytokine Res 29: 313-326, 2009.

178. Pengjam Y, Madhyastha H, Madhyastha R, Yamaguchi Y, Nakajima Y and Maruyama M: NF- $\mathrm{KB}$ pathway inhibition by anthrocyclic glycoside aloin is key event in preventing osteoclastogenesis in RAW264.7 cells. Phytomedicine 23: 417-428, 2016.

179. Hu JJ, Wang H, Pan CW and Lin MX: Isovitexin alleviates liver injury induced by lipopolysaccharide/D-galactosamine by activating Nrf2 and inhibiting NF- $\kappa$ B activation. Microb Pathog 119: 86-92, 2018.

180. Im SA, Oh ST, Song S, Kim MR, Kim DS, Woo SS, Jo TH, Park YI and Lee CK: Identification of optimal molecular size of modified Aloe polysaccharides with maximum immunomodulatory activity. Int Immunopharmacol 5: 271-279, 2005.

181. Thunyakitpisal P, Ruangpornvisuti V, Kengkwasing P, Chokboribal J and Sangvanich P: Acemannan increases NF- $\kappa$ B/DNA binding and IL-6/-8 expression by selectively binding Toll-like receptor-5 in human gingival fibroblasts. Carbohydr Polym 161: 149-157, 2017.

182. Pugh N, Ross SA, ElSohly MA and Pasco DS: Characterization of Aloeride, a new high-molecular-weight polysaccharide from Aloe vera with potent immunostimulatory activity. J Agric Food Chem 49: 1030-1034, 2001.

183. Karaca K, Sharma JM and Nordgren R: Nitric oxide production by chicken macrophages activated by Acemannan, a complex carbohydrate extracted from Aloe vera. Int J Immunopharmacol 17: 183-188, 1995.

184. Lee JK, Lee MK, Yun YP, Kim Y, Kim JS, Kim YS, Kim K, Han SS and Lee CK: Acemannan purified from Aloe vera induces phenotypic and functional maturation of immature dendritic cells. Int Immunopharmacol 1: 1275-1284, 2001.

185. Zhang L and Tizard IR: Activation of a mouse macrophage cell line by acemannan: The major carbohydrate fraction from Aloe vera gel. Immunopharmacology 35: 119-128, 1996.

186. Liu S, Zhang X and Wang J: Isovitexin protects against cisplatin-induced kidney injury in mice through inhibiting inflammatory and oxidative responses. Int Immunopharmacol 83: 106437,2020

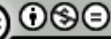

This work is licensed under a Creative Commons Attribution-NonCommercial-NoDerivatives 4.0 International (CC BY-NC-ND 4.0) License. 